\title{
Blended Learning Adoption and Implementation in Higher Education: A Theoretical and Systematic Review
}

\author{
Bokolo Anthony Jr. ${ }^{1}$ (D) Adzhar Kamaludin ${ }^{2} \cdot$ Awanis Romli ${ }^{2}$. \\ Anis Farihan Mat Raffei ${ }^{2}$ - Danakorn Nincarean A. L. Eh Phon ${ }^{2} \cdot$ Aziman Abdullah $^{2}$. \\ Gan Leong Ming ${ }^{2}$
}

Accepted: 26 September 2020 / Published online: 7 October 2020

(c) The Author(s) 2020

\begin{abstract}
Technological innovations such as blended learning (BL) are rapidly changing teaching and learning in higher education, where BL integrates face to face teaching with web based learning. Thus, as polices related to BL increases, it is required to explore the theoretical foundation of BL studies and how BL were adopted and implemented in relation to students, lecturers and administration. However, only fewer studies have focused on exploring the constructs and factors related to BL adoption by considering the students, lecturers and administration concurrently. Likewise, prior research neglects to explore what practices are involved for BL implementation. Accordingly, this study systematically reviews, synthesizes, and provides meta-analysis of 94 BL research articles published from 2004 to 2020 to present the theoretical foundation of BL adoption and implementation in higher education. The main findings of this study present the constructs and factors that influence students, lecturers and administration towards adopting BL in higher education. Moreover, findings suggest that the BL practices to be implemented comprises of face-to-face, activities, information, resources, assessment, and feedback for students and technology, pedagogy, content, and knowledge for lecturers. Besides, the review reveals that the ad hoc, technology acceptance model, information system success model, the unified theory of acceptance and use of technology, and lastly diffusion of innovations theories are the mostly employed theories employed by prior studies to explore BL adoption. Findings from this study has implications for student, lecturers and administrators by providing insights into the theoretical foundation of BL adoption and implementation in higher education.
\end{abstract}

Keywords Teaching and learning in digital environments $\cdot$ Blended learning adoption and implementation $\cdot$ Students' attitude $\cdot$ Students' perspective $\cdot$ Higher education

Bokolo Anthony Jr.

anthony.j.bokolo@ntnu.no

Extended author information available on the last page of the article 


\section{Introduction}

Blended learning (BL) has increasingly been utilized in higher education as it has the advantages of both traditional and online teaching approaches (Poon 2014). Findings from prior studies Edward et al. (2018); Ghazal et al. (2018) indicated that BL approach enhances students' learning engagement and experience as it creates a significant influence on students' awareness of the teaching mode and learning background. BL moves the emphasis from teaching to learning, thus enabling students to become more involved in the learning process and more enthused and, consequently, improves their perseverance and commitment (Ismail et al. 2018a). Poon (2014) concluded that BL is likely to be developed as the leading teaching approach for the future as one of the top ten educational trends to occur in the twentyfirst century. Poon (2014) started that the question is not whether higher education should adopt BL but rather the question should be aligned to the practice that should be included for successfully BL implementation.

The phrase blended learning was previously associated with classroom training to e-learning activities (Graham et al. 2013). Accordingly, BL is the integration of traditional face-to face and e-learning teaching paradigm (Wong et al. 2014). BL employs a combination of online-mediated and face-to-face (F2F) instruction to help lecturers attain pedagogical goals in training students to produce an algorithmic and constructive rational skill, aids to enhance teaching qualities, and achieve social order (Subramaniam and Muniandy 2019). BL entails the combination of different methods of delivery, styles of learning, and types of teaching (Kaur 2013). BL is frequently used with terms such as integrated, flexible, mixed mode, multi-mode or hybrid learning (Garrison and Kanuka 2004; Moskal et al. 2013). BL comprises integration of various initiatives, achieved by combining of $30 \%$ F2F interaction with $70 \%$ IT mediated learning (Anthony et al. 2019). Similarly, Owston et al. (2019) recommended that a successful BL delivery comprises of $80 \%$ high quality online learning integrated with $20 \%$ classroom teaching that is linked to online content. Respectively, BL is the combination of different didactic approaches (cooperative learning, discovery learning expository, presentations, etc.) and delivery methods (personal communication, broadcasting, publishing, etc.) (Graham 2013; Klentien and Wannasawade 2016).

Research has found that online systems possess the capability of providing platforms for competent practices in offering alternative to real-life environment, offering students a usable avenue for learning which support students to improve the quality of learning (Wong et al. 2014; Ifenthaler et al. 2015). When prudently and accurately deployed, IT can be deployed to achieve a reliable learning experience with practical relevancy to engage and motivate students (Tulaboev 2013). Thus, BL facilitates students to not only articulate learning but to also test on the knowledge they have attained through the semester (Aguti et al. 2013). Moreover, BL offers flexibility for students and lecturer, improved personalization, improved student outcomes, encourages growth of autonomy and self-directed learning, creates prospects for professional learning, reduced cost proficiencies, increases communication between students and lecturer, and among students (So and Brush 2008; Spring et al 2016). BL emboldens the reformation of pedagogic policies with the prospective to recapture the ideals of universities (Heinze and Procter 2004). BL seeks to produce a harmonious and coherent equilibrium between online access to knowledge and traditional human teaching by considering students' and lecturers' attitudes (Bervell and Umar 2018). BL therefore remains a significant pedagogical concept as its main focus is aligned with providing the most effective teaching and learning experience (Wang et al. 2004). 
BL offers access to online resources and information that meet the students' level of knowledge and interest. It supports teaching conditions by offering opportunities for professional collaboration, and also improve time adeptness of lecturers (Guillén-Gámez et al. 2020; Owston et al. 2019). BL proliferates students' interest in their individual learning progression (Chang-Tik 2018), facilitates students to study at their own speed, and further organize students for future by providing real-world skills (Ustunel and Tokel 2018), that assist students to directly apply their academic skills, self-learning abilities, and of course computer know how into the working force (Güzer and Caner 2014; Yeou 2016). As pointed out by Al-shami et al. (2018) BL improves social communication in university' communities, improves students' aptitude and self-reliance, increased learning quality, improve critical thinking in learning setting and incorporate technology as an operative tool to convey course contents to students (Bailey et al. 2015; Baragash and Al-Samarraie 2018a).

Existing studies mainly considered BL in the context of students and lecturers in improving teaching and learning. Prior studies paid attention to BL adoption towards improving the quality of student learning and lecturers teaching. But only fewer studies explored BL implementation process as well explored administrators' who initiate policies related to BL adoption in higher education. To fill this gap in knowledge, this current study aims to systematically reviews and synthesizes prior studies that explored BL adoption and implementation related to students, lecturers and administration based on the following six research questions:

RQ1 What are the research methods, countries, contexts, and publication year of selected BL studies?

$R Q 2$ Which BL studies proposed model related to BL adoption in higher education?

$R Q 3$ Based on RQ2 what are the theories, location, and context of the selected BL studies?

RQ4 Based on RQ3 what are the constructs of the identified theories employed to explore BL adoption in higher education?

$R Q 5$ What are the constructs and factors that influence students, lecturers and administration towards adopting BL?

RQ6 What are the practices involved for BL implementation in higher education?

Therefore, to address the research questions this study review and report on BL adoption model (constructs and factors), BL implementation processes, prior theories employed, and related studies that were mainly focused on BL adoption in relation to students, lecturers, and administrator's perspective. The remainder of the article is organized as follows. Section 2 is the literature review. Section 3 is the methodology and Sect. 4 describes the findings and discussion. Section 5 is the implications and Sect. 6 is the conclusion, limitation, and future works.

\section{Literature Review}

Learning in higher education refers to process of acquiring new knowledge, skills, intellectual abilities which can be utilized to successfully solve problems. The deployment of technologies in teaching and learning is not a new paradigm in higher education (Poon 2012). Undeniably, in the twentyfirst century students are familiar with digital environments and 
therefore lecturers are encouraged to use Information Technology (IT) in teaching to stimulate and employ students' learning (Ifenthaler and Widanapathirana 2014; Edward et al. 2018). Teaching and learning with the aid of BL practices have become a common teaching approach to involve students in learning (Garrison and Kanuka 2004). As such, BL has progressed to incorporate diverse learning strategies and is renowned as one of the foremost trends in higher education (Ramakrisnan et al. 2012). BL provides pedagogical productivity, knowledge access, collective collaborations, personal development, cost efficiency, simplifies corrections and further resolves problems related to attendance (Mustapa et al. 2015). Findings from prior studies (Wai and Seng 2015; Nguyen 2017) suggested that BL offers benefits and is also productive than traditional e-learning.

$\mathrm{BL}$ in higher education is a prevailing approach to create a more collaborative and welcoming learning environment to curb students' anxiety and fear of making mistakes (Wong et al. 2014). Adopted in universities in the late 1990s (Edward et al. 2018), it found wider acceptance in the 2000s with many more university courses offered in blended mode (Graham et al. 2013). BL employs a combination of online-mediated and face-to-face instruction to help lecturers attain pedagogical goals in training students to produce algorithmic and constructive rational skills, aids to enhance teaching qualities and achieve social order (Kaur 2013). Some researchers [such as Bowyer and Chambers (2017)] argued that technology integration in teaching promotes learning via discovery. And adds interactivity and more motivation, leading to better feedback, social interactions, and use of course materials (Sun and Qiu 2017).

As seen in Fig. 1, BL implementation usually involves F2F and other corresponding online learning delivery methods. Normally, students attend traditional lecturer-directed F2F classes with computer mediated tools to create a BL environment in gaining experiences and also promote learners' learning success and engagement (Moskal et al. 2013; Baragash and Al-Samarraie 2018b). In fact, Graham (2013); Graham et al. (2013) projected that BL will become the new course delivery model that employs different media resources to strengthen the interaction among students. BL provide motivating and meaningful learning through different asynchronous and synchronous teaching strategies such as forums, social networking, live chats, webinars, blog, etc. that provides more opportunities for reflection and feedback from students (Graham 2013; Moskal et al. 2013; Dakduk et al. 2018).

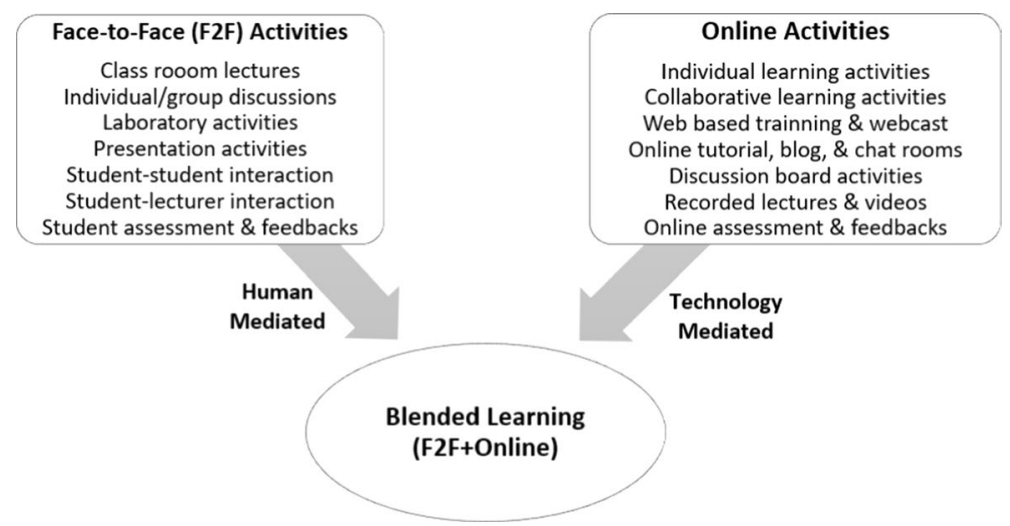

Fig. 1 Key aspects of BL derived from (Graham 2013; Moskal et al. 2013) 
BL is facilitated with virtual learning management systems such as Blackboard WebCT, Moodle, and other Web 2.0 platforms which are employed to facilitate collaborative learning between students and lecturers (Edward et al. 2018; Anthony et al. 2019). Accordingly, Aguti et al. (2014) stated that 80 percent of institutions in developed regions dynamically employ BL approach to support teaching and learning, with 97 percent of institutions reported to be deploying one or more forms of IT mediated learning. Figure 1 indicates that BL instructional design and type of delivery includes online activities such as wordbook, reading materials, online writing tool, message board, web links, tutorials, discussion forum, reference material, simulations, quizzes, etc. (Anthony et al. 2019). Conversely, F2F teaching involves lectures, laboratory activities, assessment skill practices, presentation, individual/group, and discussions carried out by the lecturer to examine the learning performance of students (Sun and Qiu 2017).

There has been rapid development in BL adoption focused on improving teaching and learning outcome, thus prior studies assessed the effectiveness of BL by comparing the traditional teaching and online teaching (Van Laer and Elen 2020). However, there are limited studies that investigated the theoretical foundation of BL adoption and implementation for teaching and learning (Wai and Seng 2015), and very limited studies focused on investigating administrative adoption related to BL. To this end, Garrison and Kanuka (2004) mentioned that it is important to examine BL adoption from the lens of institutions administrators. Researchers such as Wong et al. (2014) argued that while there are studies in BL, research that focused on BL adoption and implementation are limited, and that this is a gap to be addressed. Given the above insights, it is felt that more BL based research is needed to guide policy makers to strategically adopt BL in higher education towards improving learning and teaching. Therefore, this study systematically reviews and synthesizes prior studies that explored students, lecturers and administration adoption and implementation of BL.

\section{Methodology}

It is important to carry out an extensive literature review before starting any research investigation (Anthony et al. 2017a). Literature review finds research gaps that exists and reveals areas where prior studies has not fully explored (Anthony et al. 2017b). Likewise, a systematic literature review is a review that is based on unambiguous research questions, defines and explores pertinent studies, and lastly assesses the quality of the studies based on specified criteria (Al-Emran et al. 2018). Accordingly, this study followed the recommendation postulated by Kitchenham and Charters's (2007) in reporting a systematic review. Therefore, the research design for this study comprises of five phases which includes the specification of inclusion and exclusion criteria, presenting of search strategies and data sources, quality assessment, and data coding and analysis, and lastly findings. The research design of this review study is shown in Fig. 2.

Figure 2 depicts the research design for this study, where each phase is presented in the subsequent sub-sections.

\subsection{Inclusion and Exclusion Criteria}

The inclusion and exclusion criteria (Table 1) and quality assessment criteria (see Table 2) are employed as the sampling/selection methods used to select the articles involved in this study. The inclusion and exclusion criteria are defined in Table 1. 


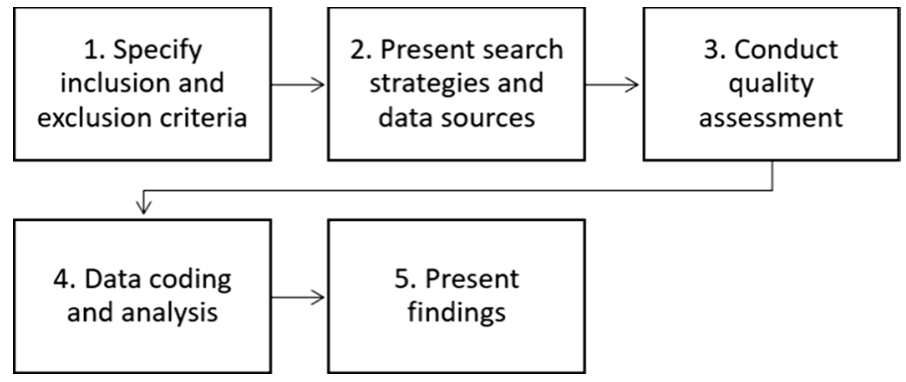

Fig. 2 Research design for SLR

\subsection{Search Strategies and Data Sources}

The articles involved in this study were retrieved through a comprehensive search of prior studies via online databases which included Google Scholar, ScienceDirect, Emerald, IEEE, Sage, Taylor \& Francis, Inderscience, Springer, and Wiley. The search was undertaken in December 2018 and March 2020. The search terms comprise the keywords (("blended learning practices" OR "blended learning variables" OR "blended learning factors" OR "blended learning constructs") AND ("implementation" OR

Table 1 Inclusion and exclusion criteria

\begin{tabular}{|c|c|}
\hline Inclusion & Exclusion \\
\hline $\begin{array}{l}\text { Should involve BL implementation practice or } \\
\text { adoption constructs/variables and factors }\end{array}$ & $\begin{array}{l}\text { Studies that do not present BL implementation prac- } \\
\text { tice or adoption constructs/variables and factors }\end{array}$ \\
\hline $\begin{array}{l}\text { Should employ a model, framework or theory for } \\
\text { investigation related to } \mathrm{BL}\end{array}$ & $\begin{array}{l}\text { Models, frameworks or theories used in contexts } \\
\text { other than BL }\end{array}$ \\
\hline $\begin{array}{l}\text { Should be written in English and published between } \\
2004 \text { and } 2020\end{array}$ & Studies that use languages other than English \\
\hline $\begin{array}{l}\text { Studies that involved BL teaching and learning in } \\
\text { relation to students, lecturers and administrators }\end{array}$ & $\begin{array}{l}\text { BL studies that do not involve students, lecturers and } \\
\text { administrators }\end{array}$ \\
\hline
\end{tabular}

Table 2 Quality assessment criteria

\begin{tabular}{ll}
\hline$\#$ & Questions \\
\hline 1 & Is the research aims plainly stated? \\
2 & Are any BL practices considered in the study? \\
3 & Are the constructs and factors considered in the study? \\
4 & Is the study context visibly specified? \\
5 & Does the article develop a model/framework or based on existing theory? \\
7 & Are the data collection methods sufficiently detailed? \\
8 & Does the article explain the reliability and validity of the variables? \\
9 & Are statistical approaches employed to analyze the data? \\
10 & Are the results clearly discussed? \\
\hline
\end{tabular}


“adoption” OR “approach" OR “model” OR "framework” OR “theory”)) AND (“components" OR "elements")). The mixture of the keywords is a crucial step in any systematic review as it defines articles that will be retrieved.

Figure 3 depicts the Preferred Reporting Items for Systematic Reviews and MetaAnalysis (PRISMA) flowchart which was employed for searching and refining of the articles as previously utilized by Al-Emran et al. (2018). The search output presented 388 articles using the above stated keywords. 93 articles were establish as duplicates, as such were removed. Therefore, resulted to 302 articles. The authors checked the articles against the inclusion and exclusion criteria and added 12 new articles based on snowballing techniques which was used to get more articles from the references of 82 studies. Accordingly, 94 research articles meet the inclusion criteria and were included in the review process. Additionally, four studies (Kitchenham and Charters 2007; Anthony et al. 2017, b; Al-Emran et al. 2018) were included in the reference since they discuss SLR process.

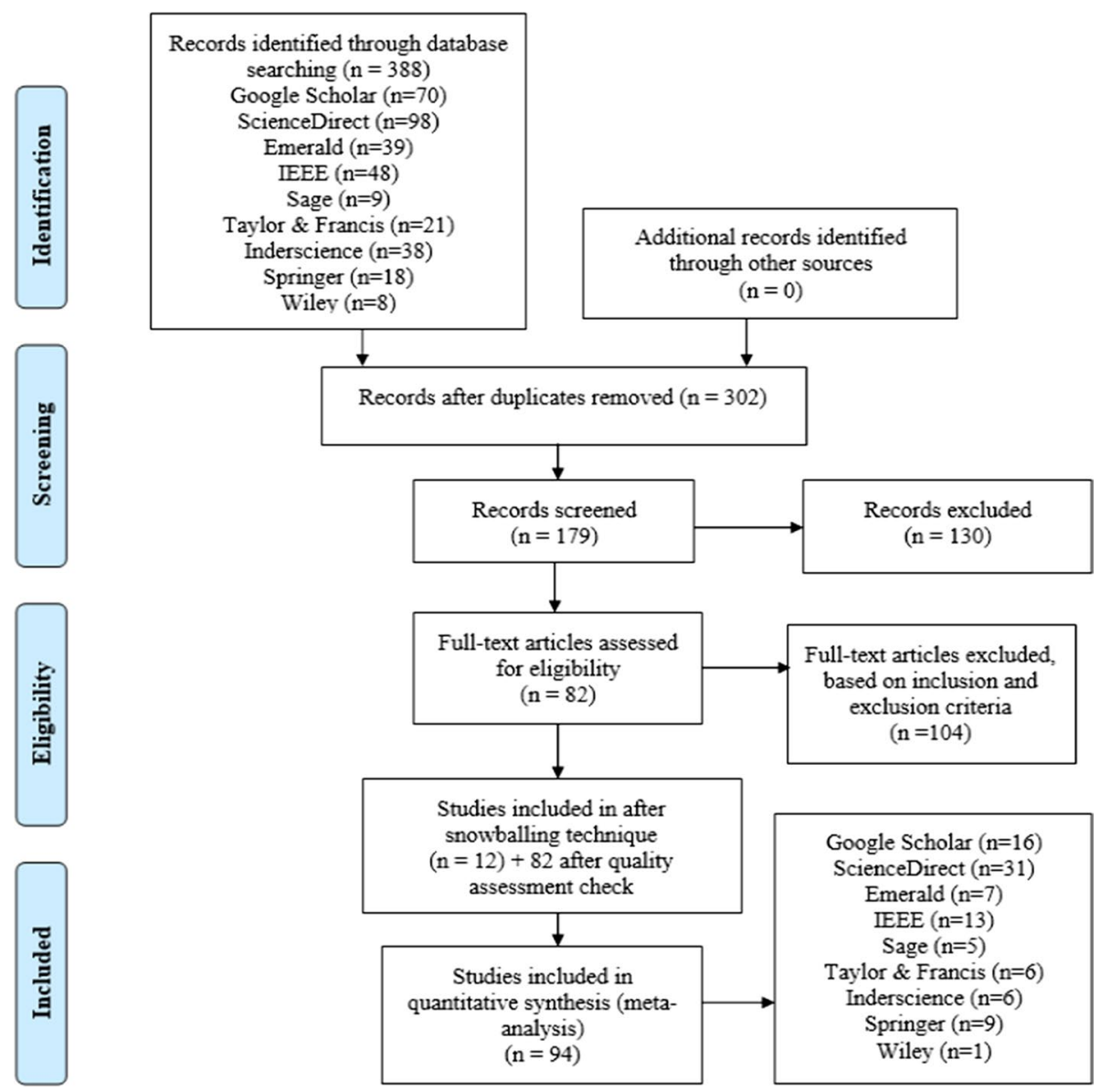

Fig. 3 PRISMA flowchart for the selected articles 


\subsection{Quality Assessment}

One of the vital determinants that are required to be checked along with the inclusion and exclusion criteria is the quality assessment. To this end, a quality assessment checklist which comprises of "10" criteria was designed and employed as a means for evaluating the quality of the studies selected $(n=94)$ (see Fig. 3 ). The quality assessment checklist is shown in Table 2. The checklist was adapted from recommendation from (Kitchenham and Charters 2007). Accordingly, the question was measured based on a 3-point scale which ranges from, 1 point being assigned for "Yes", 0 point for "No", and 0.5 point for "Partially". Hence, each article score ranges from 0 to 10 , where a study that attains higher total score, possess the capability to provide addresses the specified research questions. Table 11 in appendix shows the quality assessment results for all the 94 studies. Respectively, it is apparent that the selected studies have passed the quality assessment, which indicates that all the articles are eligible to be utilized for further meta-analysis.

\subsection{Data Coding and Analysis}

The characteristics related to the research methodology outcome were coded to include purpose of research, (BL adoption constructs and factors or BL implementation practice), research approach (e.g., literature review, conceptual, survey questionnaire, case study interviews, or experimental), country, context (e.g., student, lecturer and/or administrator), and model/framework or theory employed (e.g., Technology Acceptance Model (TAM), information system success model, the Unified Theory of Acceptance and Use of Technology (UTAUT), Diffusion of Innovations theory (DoI), Adhoc, etc.). In between the data analysis procedure, the articles that did not directly describe BL adoption model variables and implementation practices were excluded from the synthesis.

\section{Findings and Discussion}

Based on the selected 94 studies published in regard to BL adoption and implementation from 2004 to 2020, this review reports the findings of this systematic review in relation to the specified six research questions.

\subsection{RQ1: What are the Research Methods, Countries, Contexts, and Publication Year of Selected BL Studies?}

With regard to the first research question, the findings for distribution of studies related to BL adoption and implementation in higher education based on year of publication is presented in Fig. 4. As shown, the studies are ranged from 2004 to 2020. Findings from Fig. 4 indicate that there seems to be an increase in studies on BL over the last few years as seen from 2004 to 2020 , with 2018 being the highest with publications on BL adoption and implementation with 17 studies published. It is evident that the frequency of these publications in 2018 could be accredited to the fact that the intensity of BL implementation in 2018 across higher education has improved mainly in developed and developing countries across the world. 


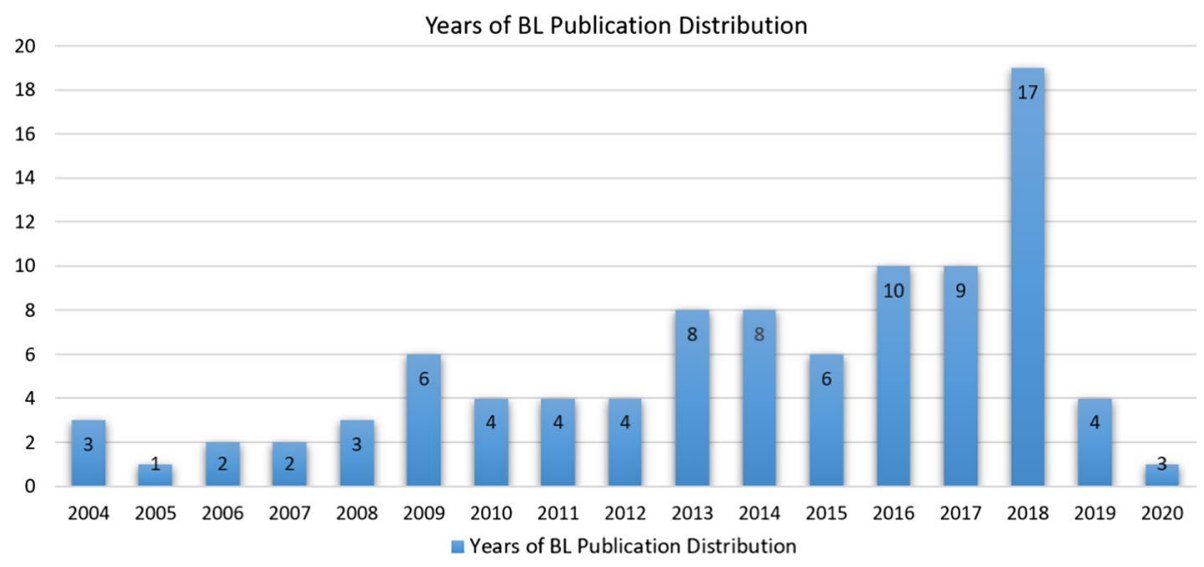

Fig. 4 Distribution of selected BL studies in terms of years

Considering the research methodology applied in the 94 BL studies, findings from Fig. 5 show that questionnaire survey is the most employed method for data collection $(\mathrm{N}=49$, $62 \%)$, followed by studies that were conceptual by design with $(\mathrm{N}=14,16 \%)$. Next, is studies that adopted mixed method both survey and interview with $(\mathrm{N}=11,13 \%)$ and studies that are qualitative in nature as case study/interview with $(\mathrm{N}=8,9 \%)$. For the remaining studies $(\mathrm{N}=5,5 \%)$ employed experimental using LMS dataset, $(\mathrm{N}=4,4 \%)$ conducted literature review, and lastly only $(\mathrm{N}=1,1 \%)$ study deployed a mixed experimental and survey approach. These findings are analogous with the prior review studies conducted by (Holton

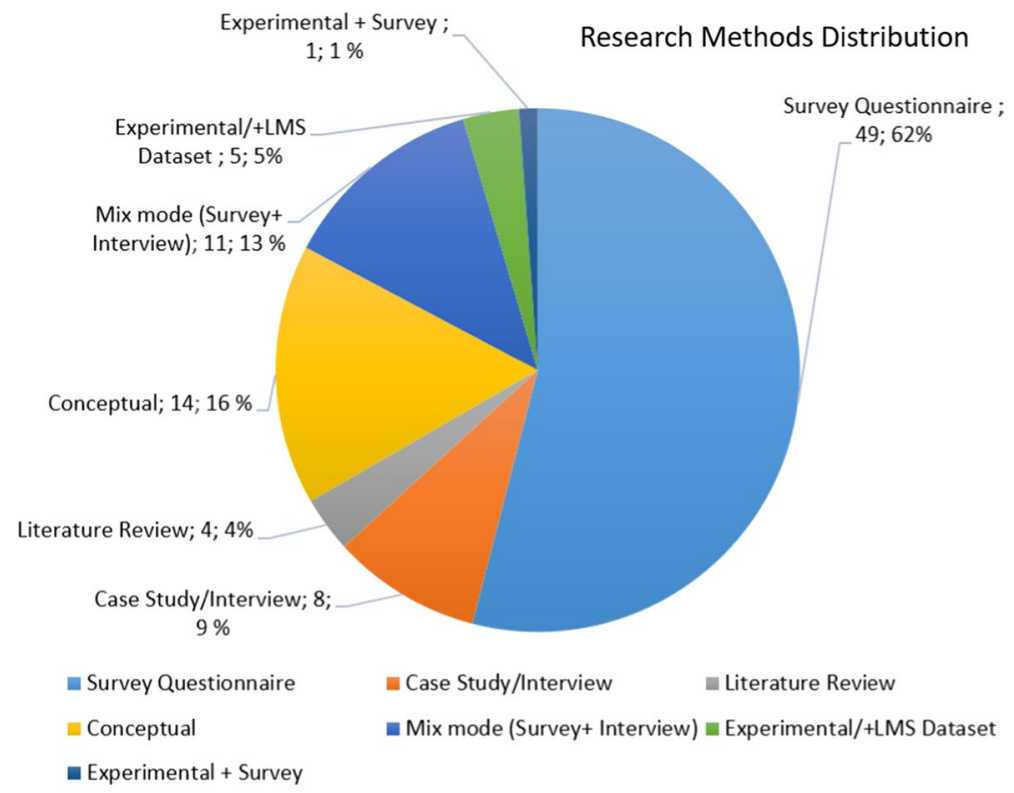

Fig. 5 Distribution of selected BL studies in terms of research methods 
III et al. 2006; Kumara and Pande 2017) who discussed that quantitative studies were the main approach employed in prior BL studies. Furthermore, this finding is consistent with the fact that surveys are considered as the most suitable tool to collect data in validating constructs/factors in developed BL adoption model in investigating students and lecturers' perceptions towards BL practice in higher education (Ghazali et al. 2018; Ismail et al. 2018b).

With regard to the $94 \mathrm{BL}$ studies country distribution, findings from Fig. 6 shows research related to BL adoption in higher education. Accordingly, most of the studies are conducted in Malaysia $(\mathrm{N}=28)$, this is based on the fact that the Malaysia ministry of education initiated an educational blueprint for all higher education to adopt BL from 2015 to 2022. Therefore, there were several studies that proposed models to examine BL adoption in universities in Malaysia context. Next, research articles related to BL adoption was carried out in United States of America with $(\mathrm{N}=11)$, and Australia $(\mathrm{N}=10)$ and United Kingdom with $(\mathrm{N}=7)$, followed by Turkey with $(\mathrm{N}=4)$, Canada, Indonesia, and Spain with $(\mathrm{N}=3)$ respectively. Additionally, Fig. 6 indicates that $(\mathrm{N}=2)$ studies were conducted in Norway, Dubai, UAE, India, Singapore, Saudi Arabia, and Taiwan. Lastly, $(\mathrm{N}=1)$ study was each conducted in Greece, Germany, Philippines, South Korea, The Netherlands, Thailand, Vietnam, Belgium, Bulgaria, China, Poland, Israel, Morocco, Colombia, Sri Lanka, and Ghana. This finding also suggest that most of the first researchers of BL adoption such as Garrison and Kanuka (2004), Graham et al. (2013), Poon (2014) and Porter and Graham (2016) are from USA, Canada, Australia and UK who are one of the most cited researchers in BL practice in higher education as compared to other regions.

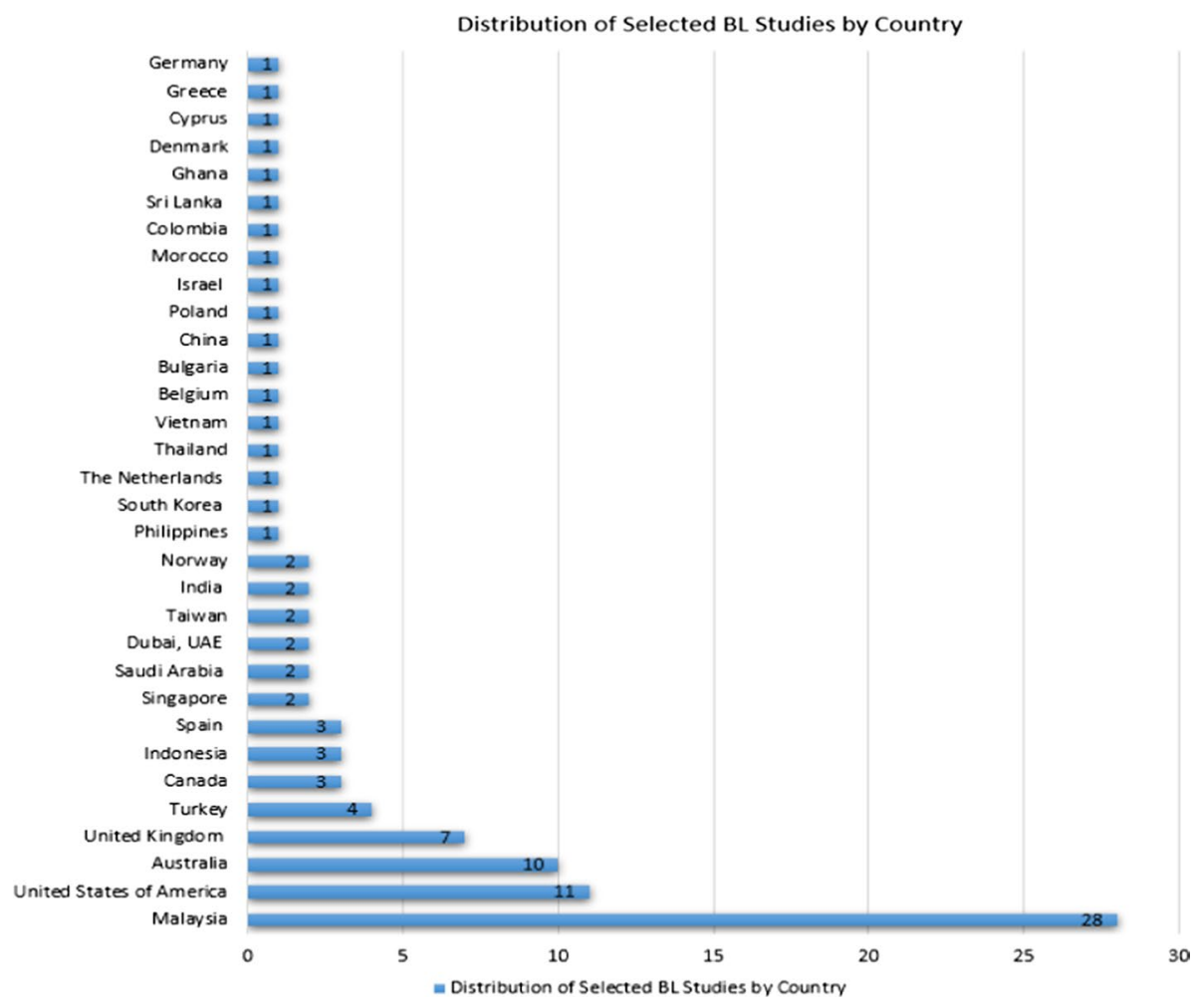

Fig. 6 Distribution of selected BL studies in terms of countries 
Considering the selected studies context distribution of BL adoption in higher education findings from Fig. 7 indicate that $(\mathrm{N}=59,62 \%)$ studies mainly examined BL adoption by considering students perspective. This finding is consistent with results from prior studies (Wai and Seng 2013; Rahman et al. 2015) which advocated for the need for developing a model of measuring student satisfaction, perception (So and Brush 2008), commitment (Wong et al. 2014), effectiveness (Wai and Seng 2015) in the BL. In addition, findings from Fig. 7 reveal that $(\mathrm{N}=9,10 \%)$ studies mainly examined BL adoption by considering lecturers perspective. This finding is very consistent with results from the literature (Wong et al. 2014; Zhu et al. 2016), where the authors mentioned the need for a study to investigate the current level of adoption of BL among the academicians to identify the factors that influence BL adoption.

Furthermore, the findings suggest that $(\mathrm{N}=7,8 \%)$ studies mainly examined BL adoption by considering administrative perspective. Similarly, this finding is analogous with results from qualitative studies conducted by prior researchers (Koohang, 2008; Graham et al. 2013; Porter et al. 2016; Bokolo Jr et al. 2020) which revealed that there are limited studies that explored policy and governance issues related BL adoption. Additionally, findings from Fig. 7 show that $(\mathrm{N}=10,10 \%)$ studies that concurrently examined $\mathrm{BL}$ in the context of students and lecturers, this aligns with findings presented by Brahim and Mohamad (2018); Edward et al. (2018) where the authors called for the need for empirical evidence on BL implementation to improve academic activities. Lastly, $(\mathrm{N}=9,10 \%)$ studies investigated BL in the context of student, lecturer, and administrators. This finding suggests that there are limited studies that examine students, lectures and administrators simultaneously as mentioned by (Machado 2007; Wong et al. 2014; Bokolo Jr et al. 2020). Accordingly, this review presents the constructs and factors that influence BL adoption from the perspective of students, lecturers, and administrators in higher education.

\subsection{RQ2: Which BL Studies Proposed Model Related to BL Adoption in Higher Education?}

Several studies have been carried out directed towards investigating the adoption of BL in higher education. Thus, Table 3 shows that out of the selected 94 studies only 51 studies developed models to examine BL where each study is compared based on the authors, contribution, purpose and identified factors/attributes and methods.

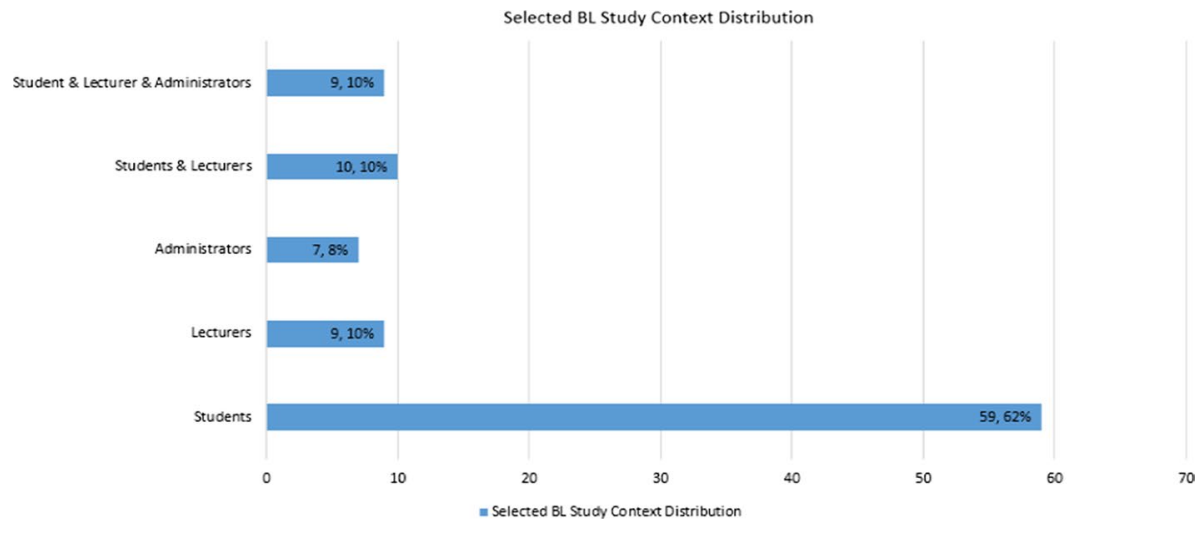

Fig. 7 Distribution of selected BL studies context 
Based on the selected $51 \mathrm{BL}$ studies that develop a research model to examine BL adoption in higher education, the review indicates that none of the studies is concerned with BL practices to be implemented in higher education, they are mainly concerned about BL adoption factors/attributes. As seen in Fig. 8 out of the reviewed 51 BL studies that developed models to examine BL adoption. The results suggest that survey questionnaire was most employed, whereas experimental and survey was least employed to validate the developed models. Also, Fig. 9 presents the clustered of issues addressed in the reviewed 51 BL studies. The identified factors/attributes derived from the reviewed $51 \mathrm{BL}$ studies are presented in Fig. 10 and further discussed in Tables 6, 7 and 8.

\subsection{RQ3: Based on RQ2 What are the Theories, Location, and Context of the Selected BL Studies?}

Among the selected $51 \mathrm{BL}$ studies, this sub-section presents prior theories that have been utilized to examine BL adoption in higher education. Moreover, the location and BL context of the 51 BL studies are presented as seen in Table 4.

Findings from Table 4 and Fig. 11 indicate that out of the reviewed 51 BL studies, $(\mathrm{N}=37,72 \%)$ studies investigated $\mathrm{BL}$ by considering the students context similar to previous studies Tuparova and Tuparov (2011); Roszak et al. (2014), while ( $\mathrm{N}=2,4 \%)$ studies examined BL by considering only lecturers' context. Besides, $(\mathrm{N}=4,8 \%)$ studies only examined administration context analogous with prior study Mercado (2008), while another $(\mathrm{N}=6,12 \%)$ studies examined BL by considering the students and lecturers context similar to prior studies Maulan and Ibrahim (2012); Mohd et al. (2016). Lastly, ( $\mathrm{N}=2$, 4\%) studies examined BL by considering the students, lecturers and administration context analogous to research conducted by Mercado (2008); Anthony et al. (2019). Hence, it is evident that there are fewer studies that investigated BL adoption by concurrently exploring students, lecturers and administration viewpoint. Thus, this review aims to address this limitation by reviewing theoretical foundation of BL adoption and implementation in the lens of students, lecturers and administration.

\subsection{RQ4: Based on RQ3 What are the Constructs of the Identified Theories Employed to Explore BL Adoption in Higher Education?}

This sub-section reviews the constructs of theories employed by the selected $51 \mathrm{BL}$ studies in developing their model as seen in Table 5.

Based on Tables 4 and 5, Fig. 12 depicts the frequency of how many times each theory has been employed by prior BL studies. Findings from theories employed show that ad hoc is the most employed approach with $(\mathrm{N}=23,42 \%)$ studies, followed by TAM with $(\mathrm{N}=7,13 \%)$ studies, IS success model and UTAUT with $(\mathrm{N}=4,7 \%)$ studies individually, and DoI with $(\mathrm{N}=3,5 \%)$ studies, whereas the other theories were adopted by $(\mathrm{N}=1,2 \%)$ study respectively.

\subsection{RQ5: What are the Constructs and Factors that Influence Students, Lecturers and Administration towards Adopting BL?}

The constructs and factors related to the adoption of BL by students, lecturers and administrators are shown in Fig. 13 and described in Table 6. 


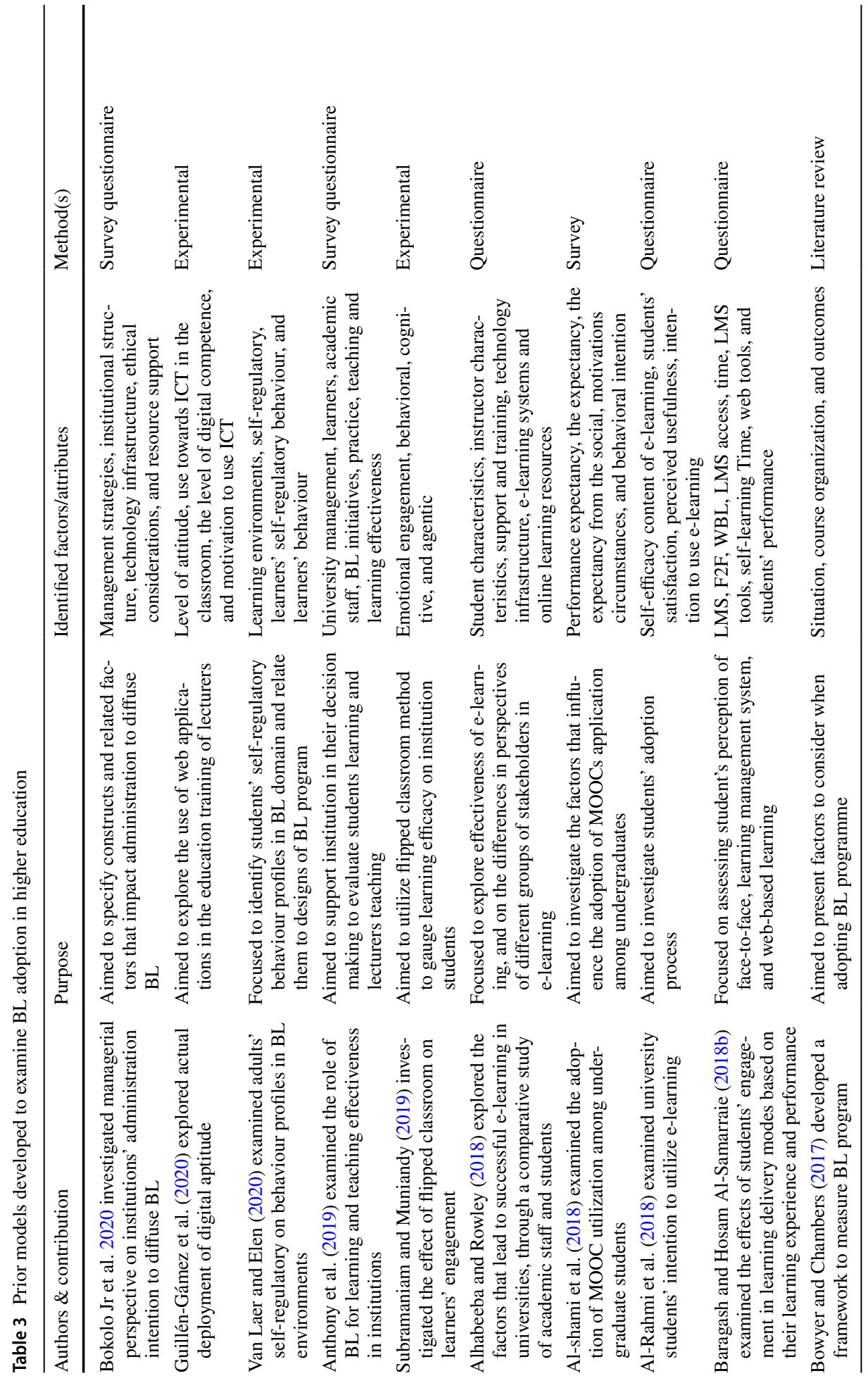




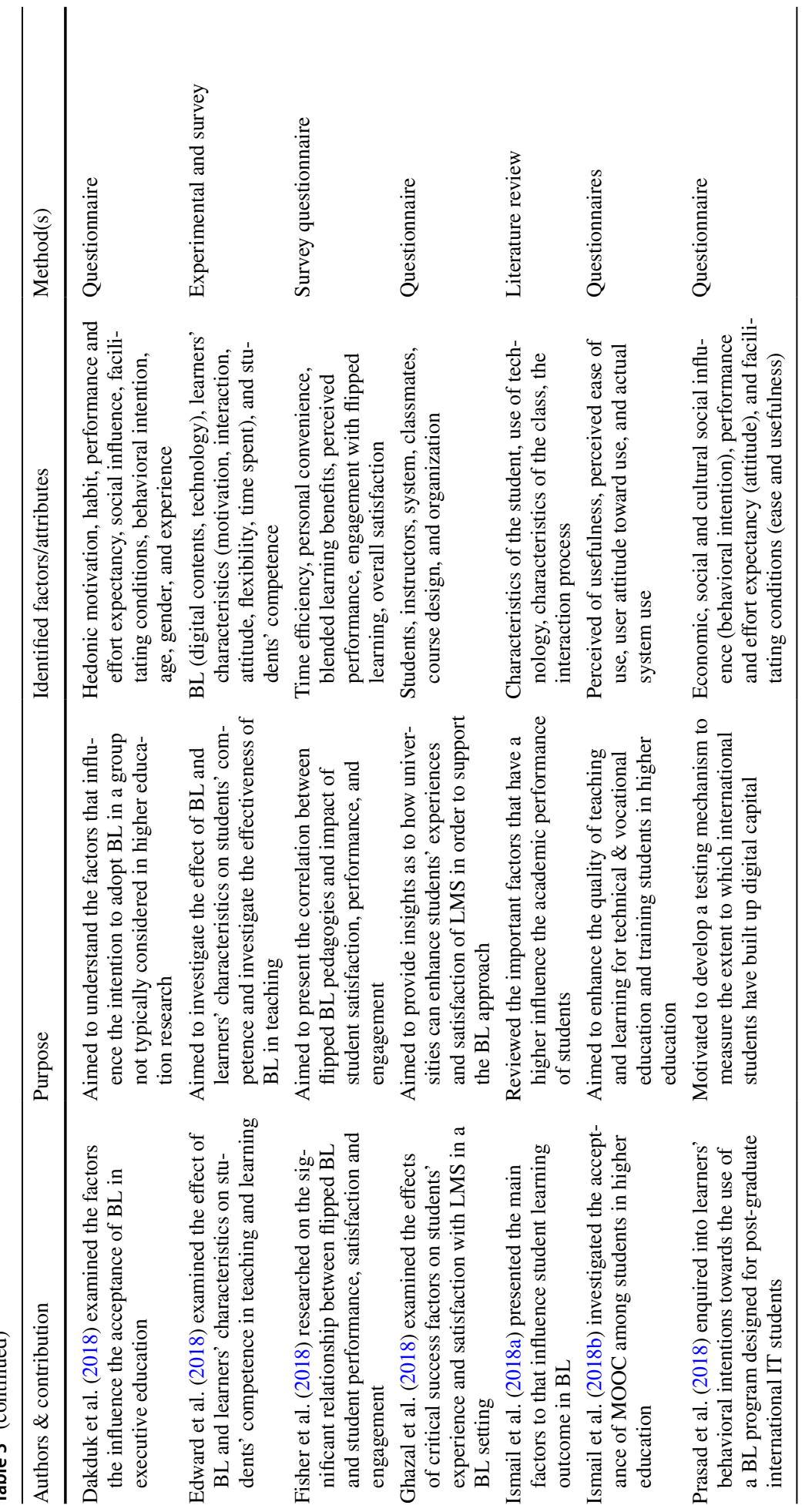




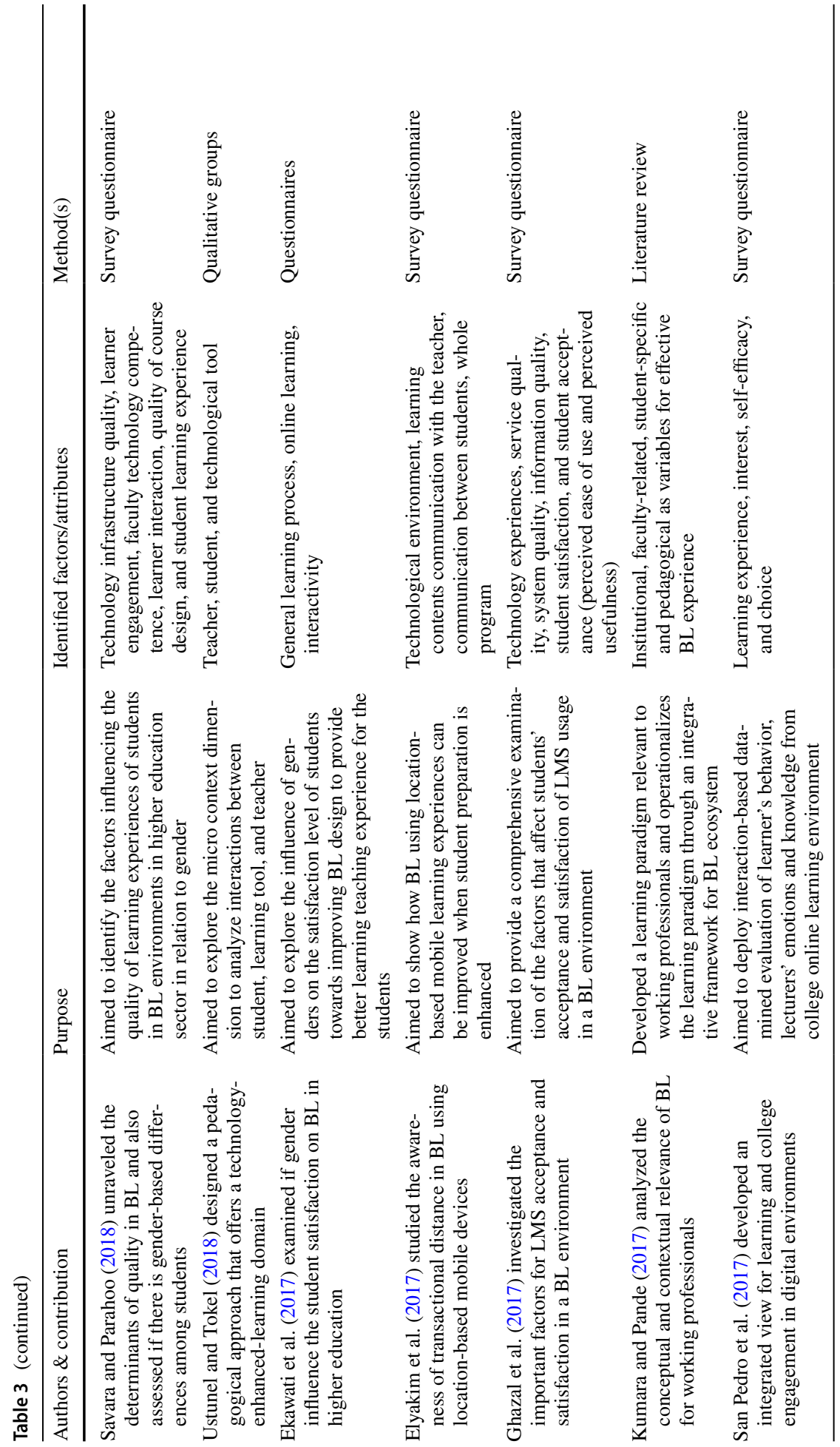




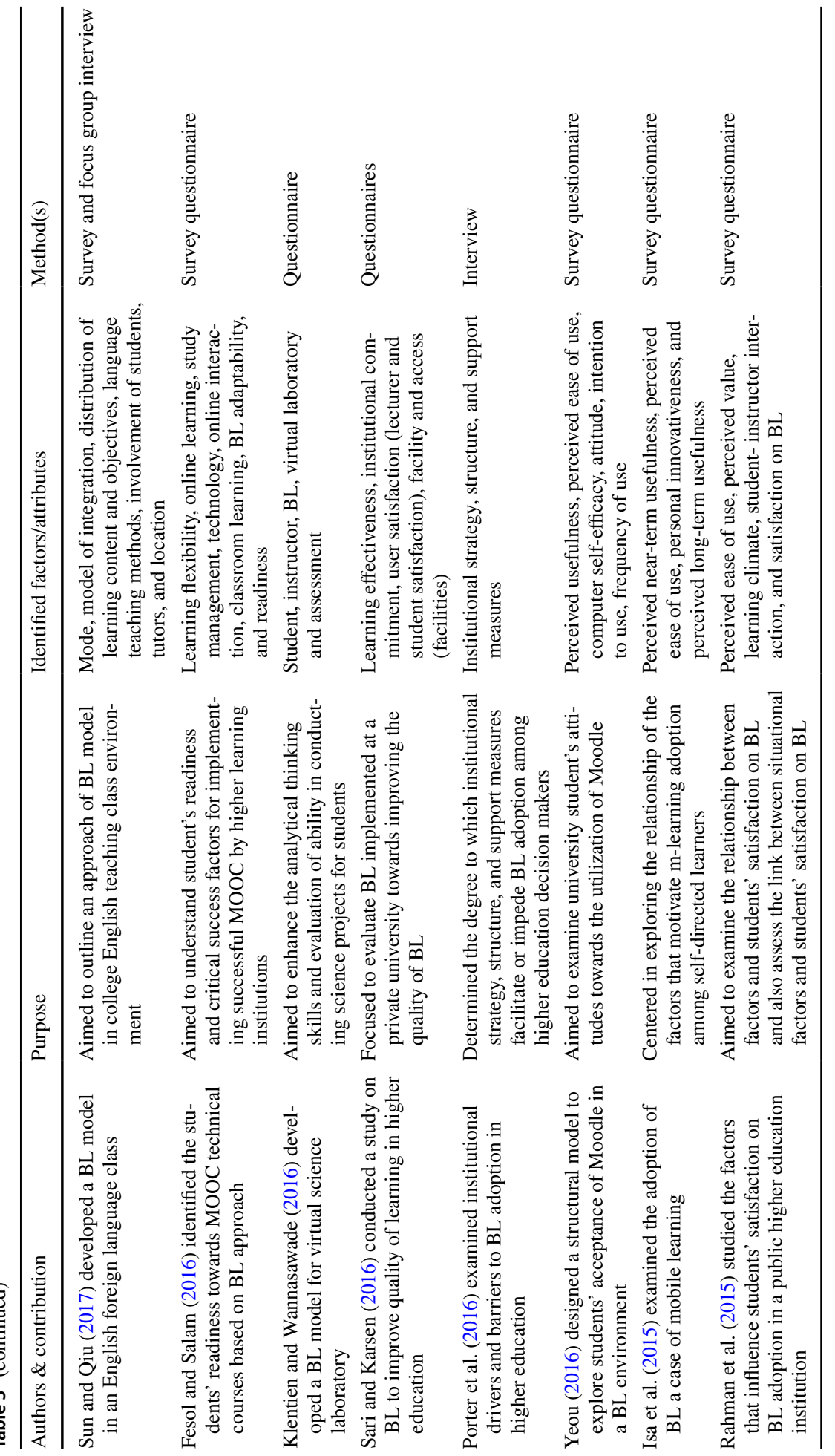




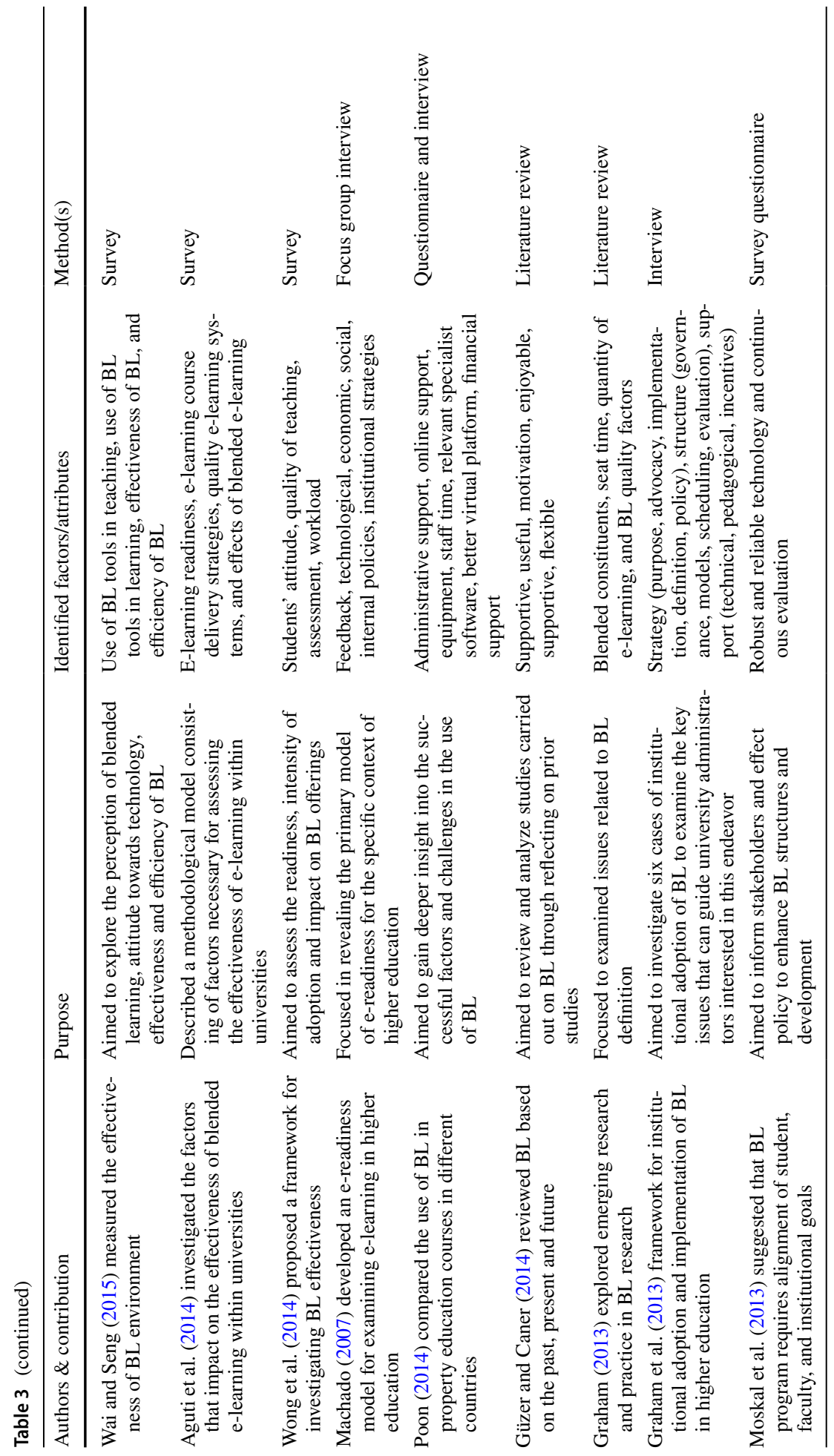




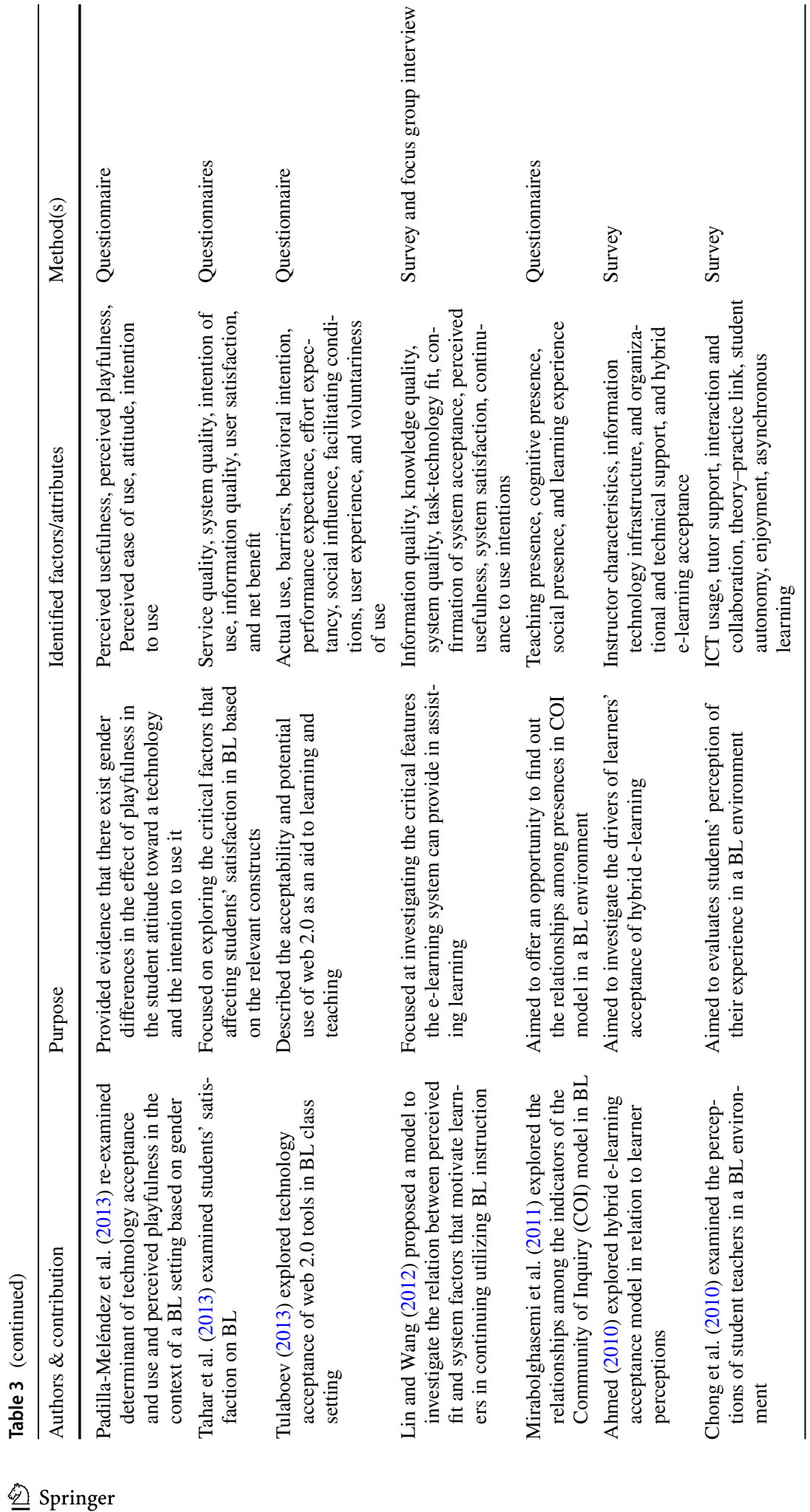




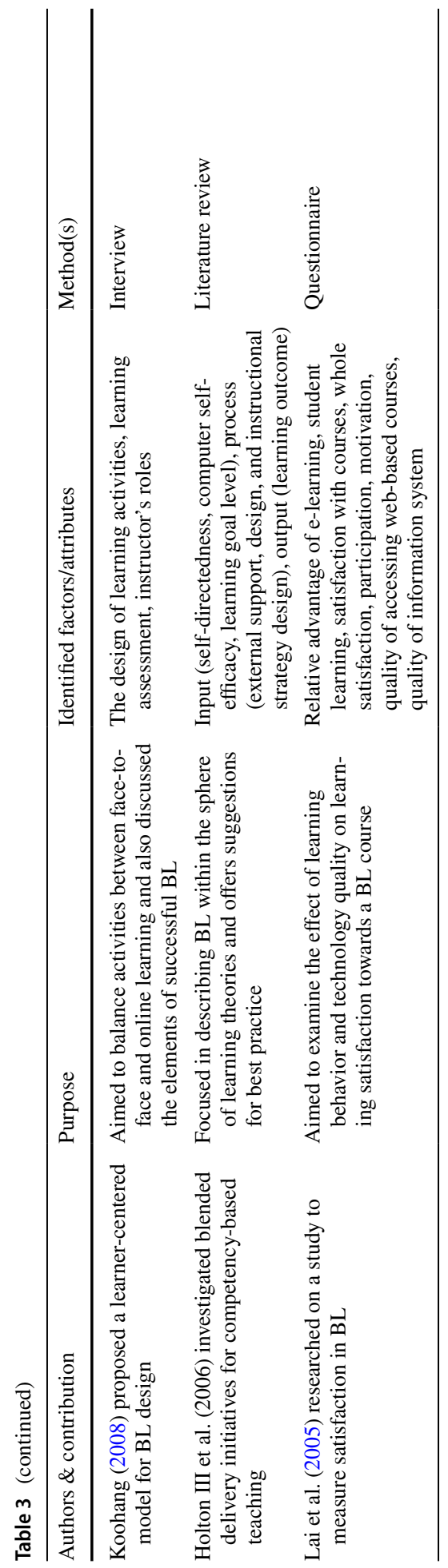




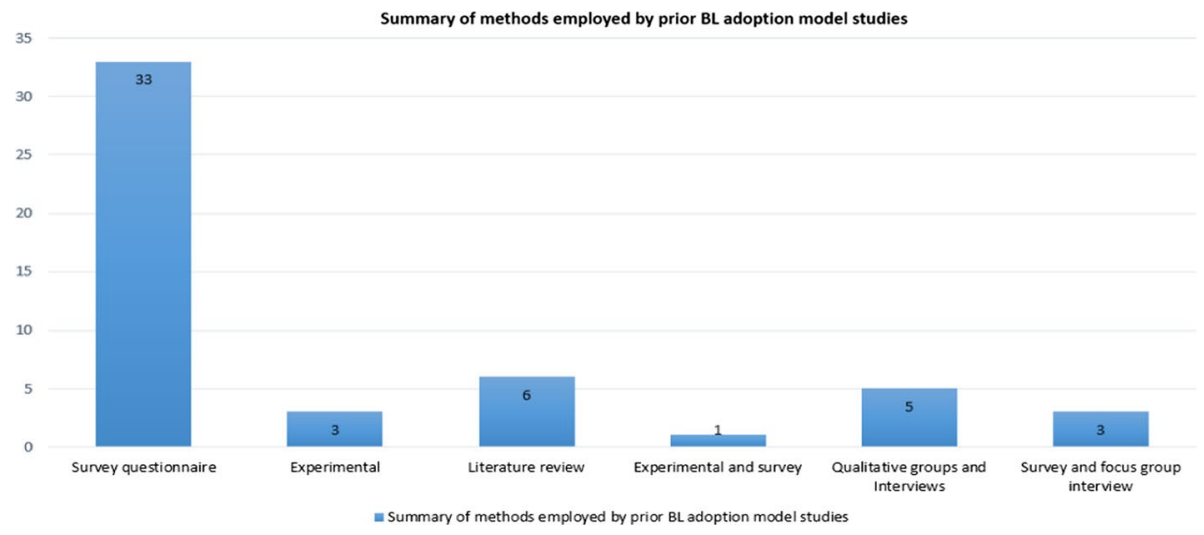

Fig. 8 Distribution of the reviewed 51 BL studies that developed BL adoption models

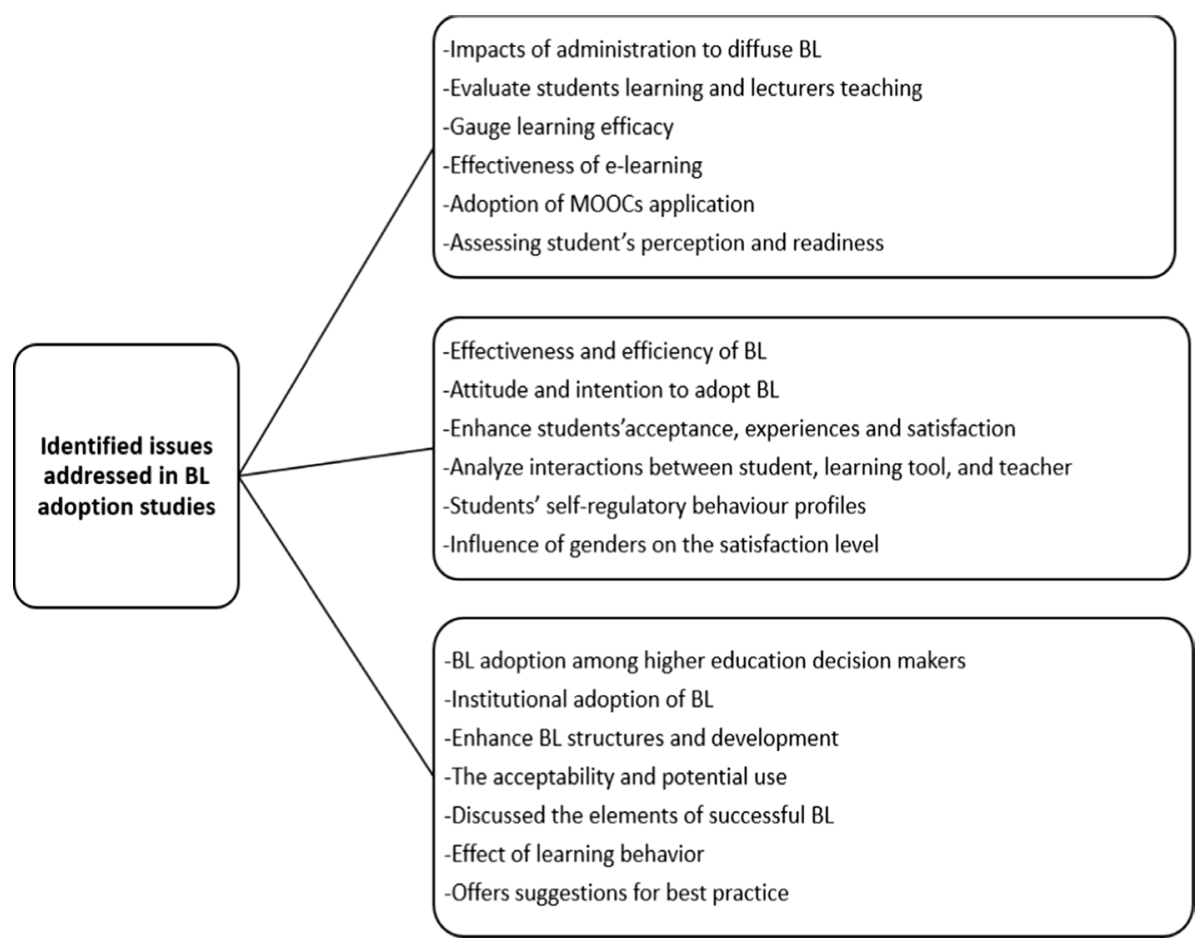

Fig. 9 Clustering of issues addressed in the reviewed BL adoption studies

Tables 6, 7 and 8 describes the derived constructs for students, lecturers, and administration related to $\mathrm{BL}$ adoption in higher education. BL adoption cannot be attained by only integrating online and face-to-face teaching modes (Azizan 2010). Thus, there is need to identify the constructs that influence students, lecturer, and administration in adopting $\mathrm{BL}$ practices to be implemented that play an important role in ensuring successful BL 


\begin{tabular}{|c|c|c|}
\hline Administrators & Lecturers & Students \\
\hline $\begin{array}{l}\text {-Strategies } \\
\text {-Structure } \\
\text {-Technology infrastructure } \\
\text {-Ethical considerations } \\
\text {-Resource support } \\
\text {-Purpose } \\
\text {-Advocacy } \\
\text {-Definition } \\
\text {-Policy } \\
\text {-Governance } \\
\text {-Scheduling } \\
\text {-Evaluation } \\
\text {-Technical } \\
\text {-Pedagogical } \\
\text {-Incentives }\end{array}$ & $\begin{array}{l}\text {-Service quality } \\
\text {-System quality } \\
\text {-Information quality } \\
\text {-User satisfaction } \\
\text {-Net benefit } \\
\text {-Teaching effectiveness } \\
\text {-Facilitating conditions } \\
\text {-Experience } \\
\text {-Motivation } \\
\text {-Satisfaction } \\
\text {-Experience } \\
\text {-Flexibility } \\
\text {-Adaptability } \\
\text {-Commitment } \\
\text {-Supportive }\end{array}$ & $\begin{array}{l}\text {-Perceived ease of use } \\
\text {-User attitude toward use } \\
\text {-Actual system use } \\
\text {-Self-efficacy } \\
\text {-Emotional engagement } \\
\text {-Behavioral cognitive } \\
\text {-Satisfaction } \\
\text {-Perceived usefulness } \\
\text {-Continuance intention to use } \\
\text {-Frequency of use } \\
\text {-Enjoyable } \\
\text {-Learning effectiveness } \\
\text {-Hedonic motivation } \\
\text {-Habit } \\
\text {-Age } \\
\text {-Gender } \\
\text {-Performance expectancy } \\
\text {-Effort expectancy } \\
\text {-Social influence } \\
\text {-Flexibility }\end{array}$ \\
\hline
\end{tabular}

Fig. 10 Identified factors/attributes derived in the reviewed BL adoption studies

experience in higher education (Graham 2013; Güzer and Caner 2014). On this note, academicians such as Machado (2007); Wong et al. (2014); Kumara and Pande (2017); Bokolo Jr et al. (2020) highlighted that successful implementation of BL initiatives requires an alignment between administrative, lecturers, students' educational goals. According to Dakduk et al. (2018); Anthony et al. (2019) it is importance to examine constructs related to human computer interaction to assess which constructs contributes to realizing the desired teaching and learning objectives while engaging the lecturers and students. Therefore, this study explores the BL practices to be implemented by students and lecturers in higher education as seen in Figs. 14 and 15.

\subsection{RQ6: What are the Practices Involved for BL Implementation in Higher Education?}

The practice to be carried out by students for implementing BL in higher education is shown in Fig. 14.

Figure 14 depicts BL practice implementation for students in higher education. According to Kaur and Ahmed (2006); Kaur (2013) the recommended balance of BL activities for successful delivery is $80 \%$ online learning (activities, information, resources, assessment and feedback) followed by $20 \%$ classroom instruction (face to face) that is aligned to the online teaching content. Similarly, Ginns and Ellis (2007) 


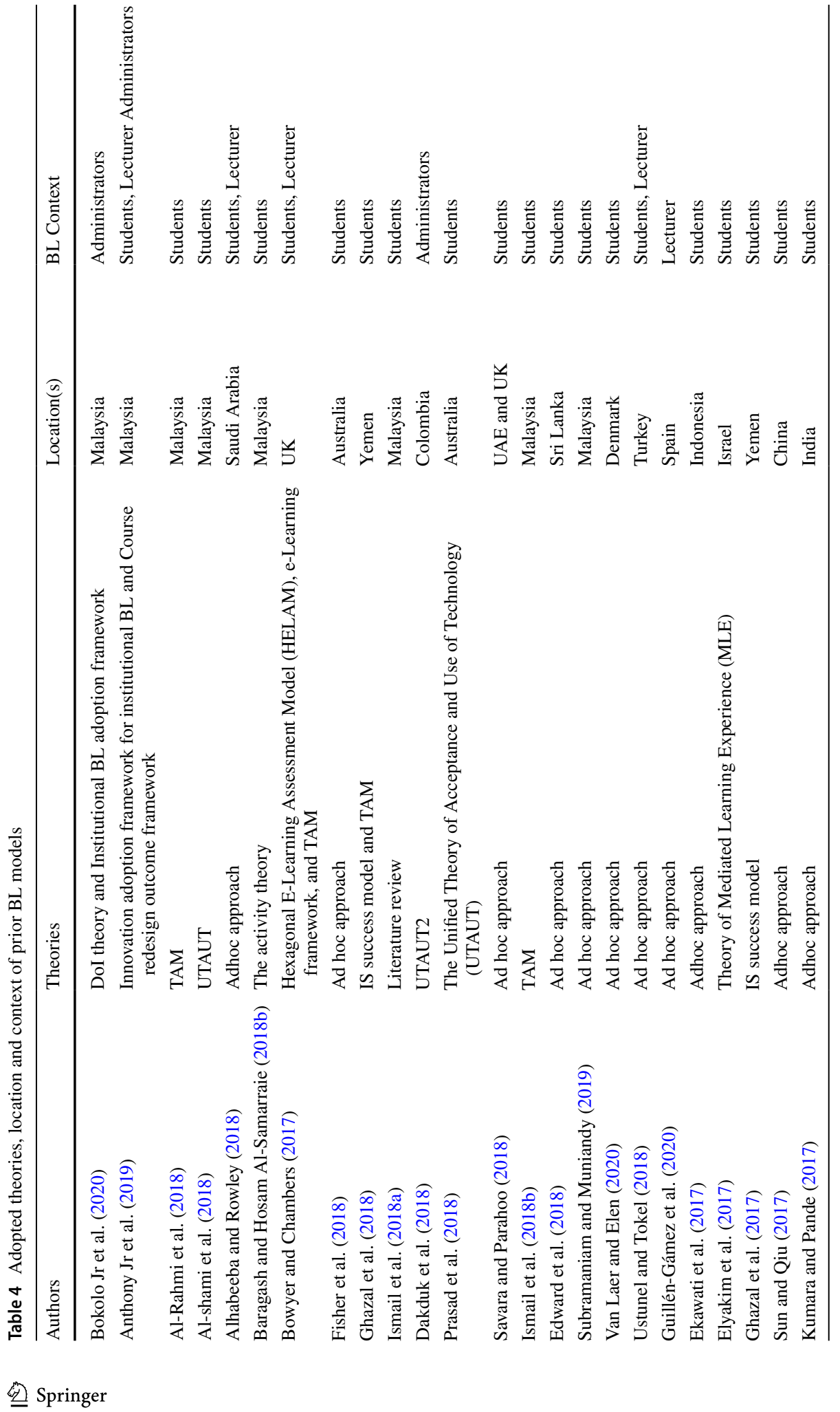




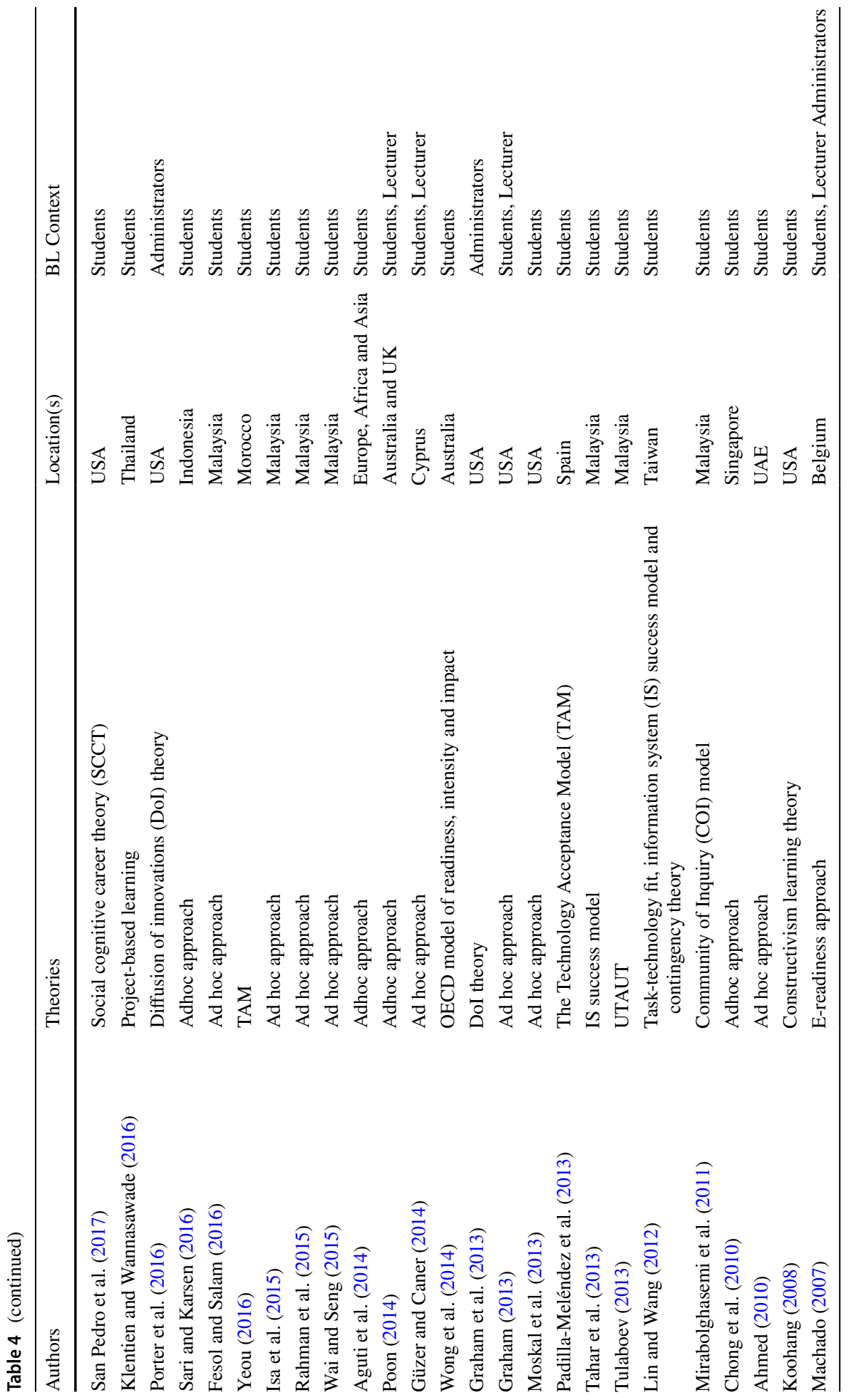




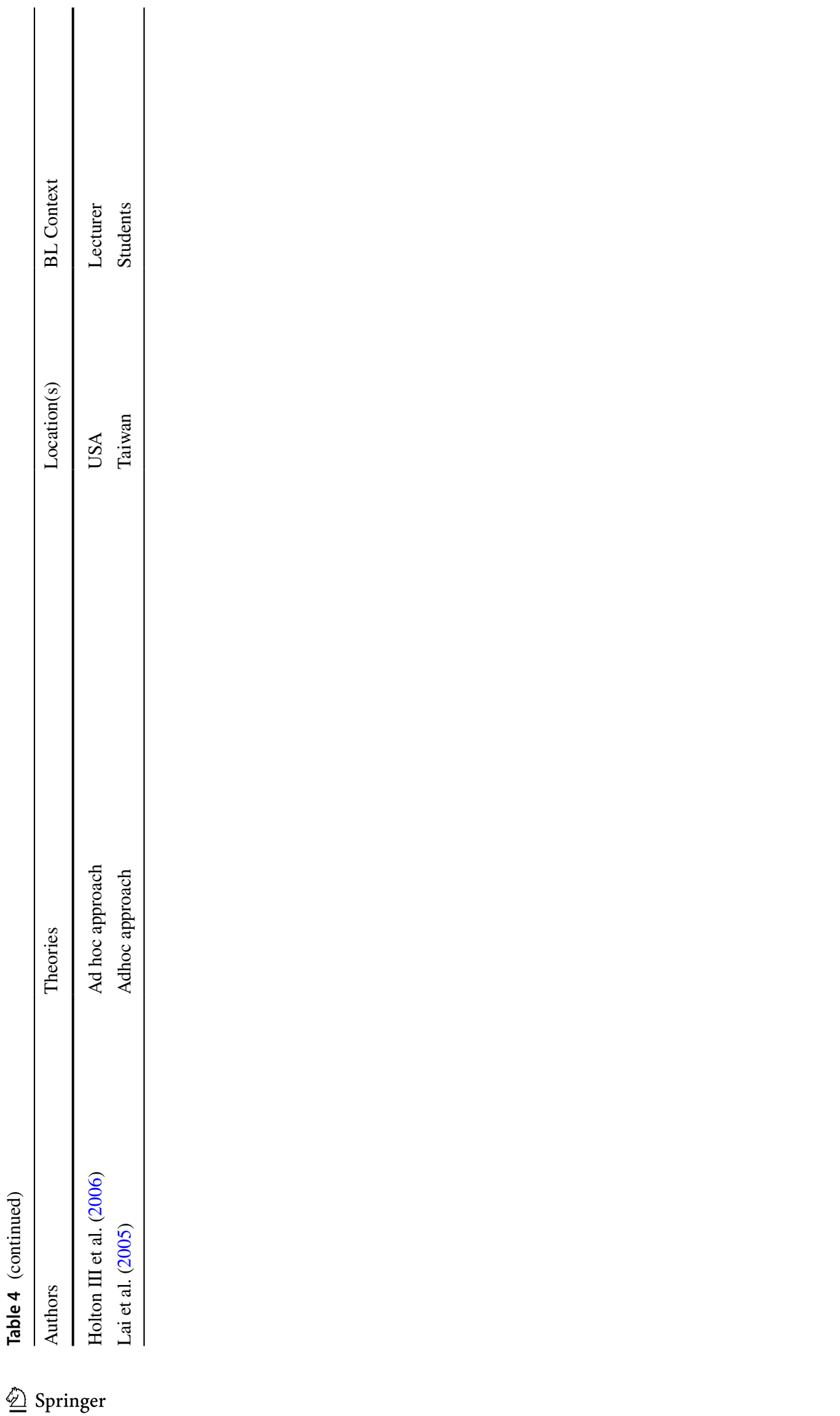




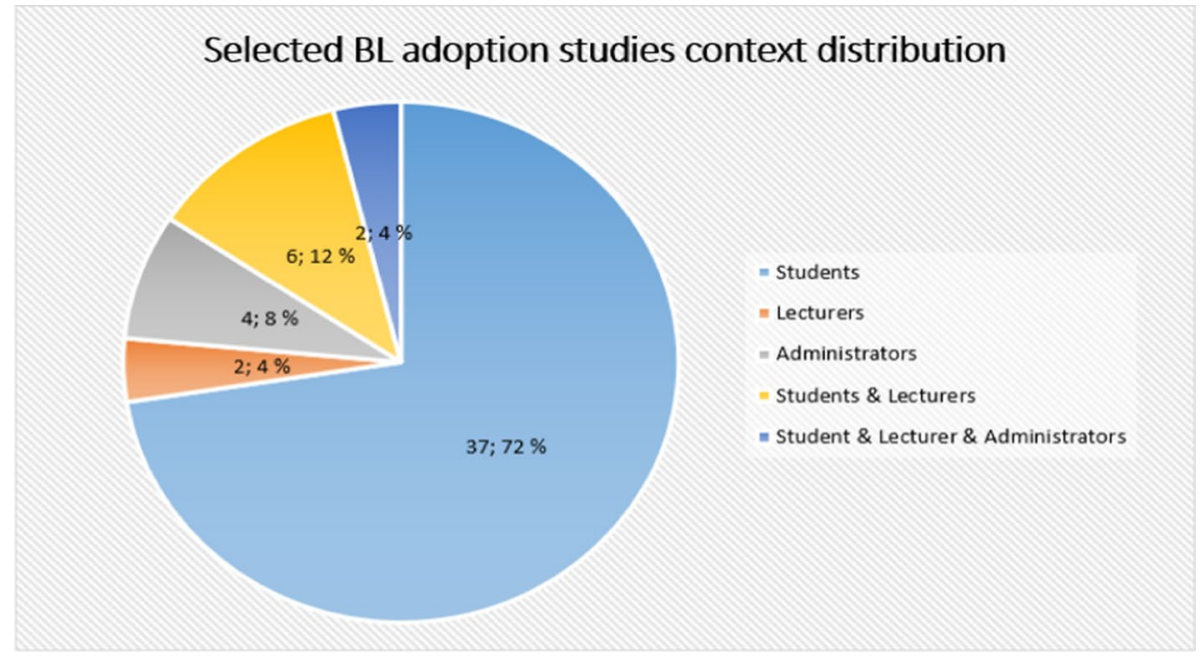

Fig. 11 Selected BL adoption studies context distribution

argued that for an effective BL initiative it is required to achieve a blend of 29-30\% face to face and $79-80 \%$ on-line teaching delivery. This is in line with findings from previous studies (Graham et al. 2013; Bokolo Jr et al. 2020), which states that there is need for policies showing clear decrease of face to face classroom hours and increasing online learning as a strategy to enhance BL implementation in higher education (Park et al. 2016). Further description of BL implementation for students is discussed in Table 9.

Figure 15 depicts BL practice implementation for lecturers in higher education. The BL practice is based on the Technology, Pedagogy, and Content Knowledge (TPACK) framework proposed by Koehler and Mishra (2009). TPACK aimed address issues faced by how lecturers can integrate technology into their current teaching (Wang et al. 2004; Sahin 2011). Thus, TPACK offers a method that indulgences teaching as collaboration between what lecturers know and how they teach and apply what they already know uniquely through BL implementation in the contexts of physical and online classes (Graham et al. 2009; Koehler and Mishra 2009). Further description of TPACK the components in relation to BL implementation is discussed in Table 10.

\section{Implications for Theory, Methodology and Pedagogical Practice}

Findings from this study offer implications for theory, methodology and pedagogical practice for higher education towards adopting BL.

\subsection{Implications for Theory}

Theoretically, this study identifies the factors that influence students, lecturers and administrators' towards adopting BL. Our findings provide insight by revealing factors for higher education to better recognize how BL can be delivered towards the development of students' learning effectiveness and also offering in-depth understanding of BL 


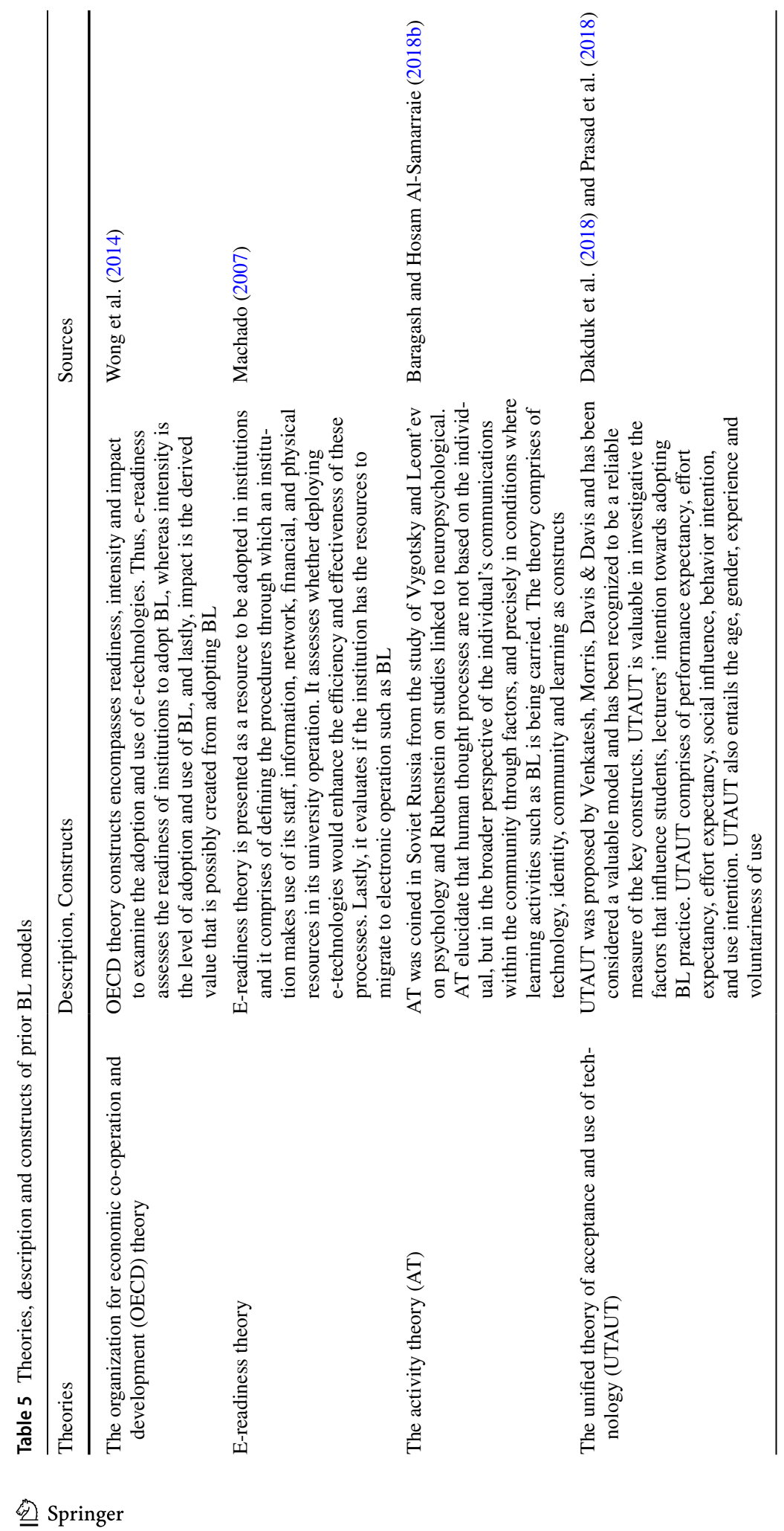




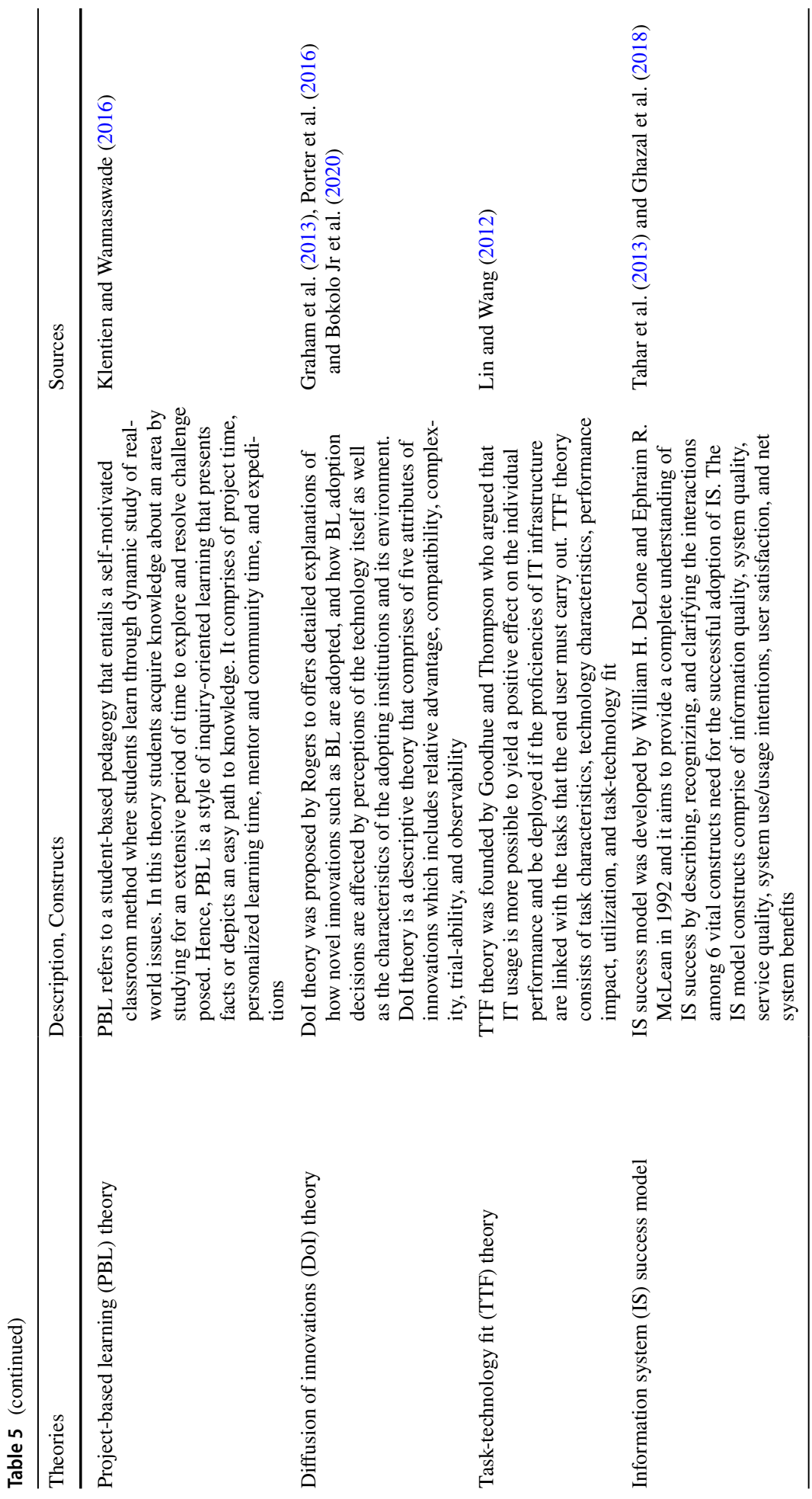




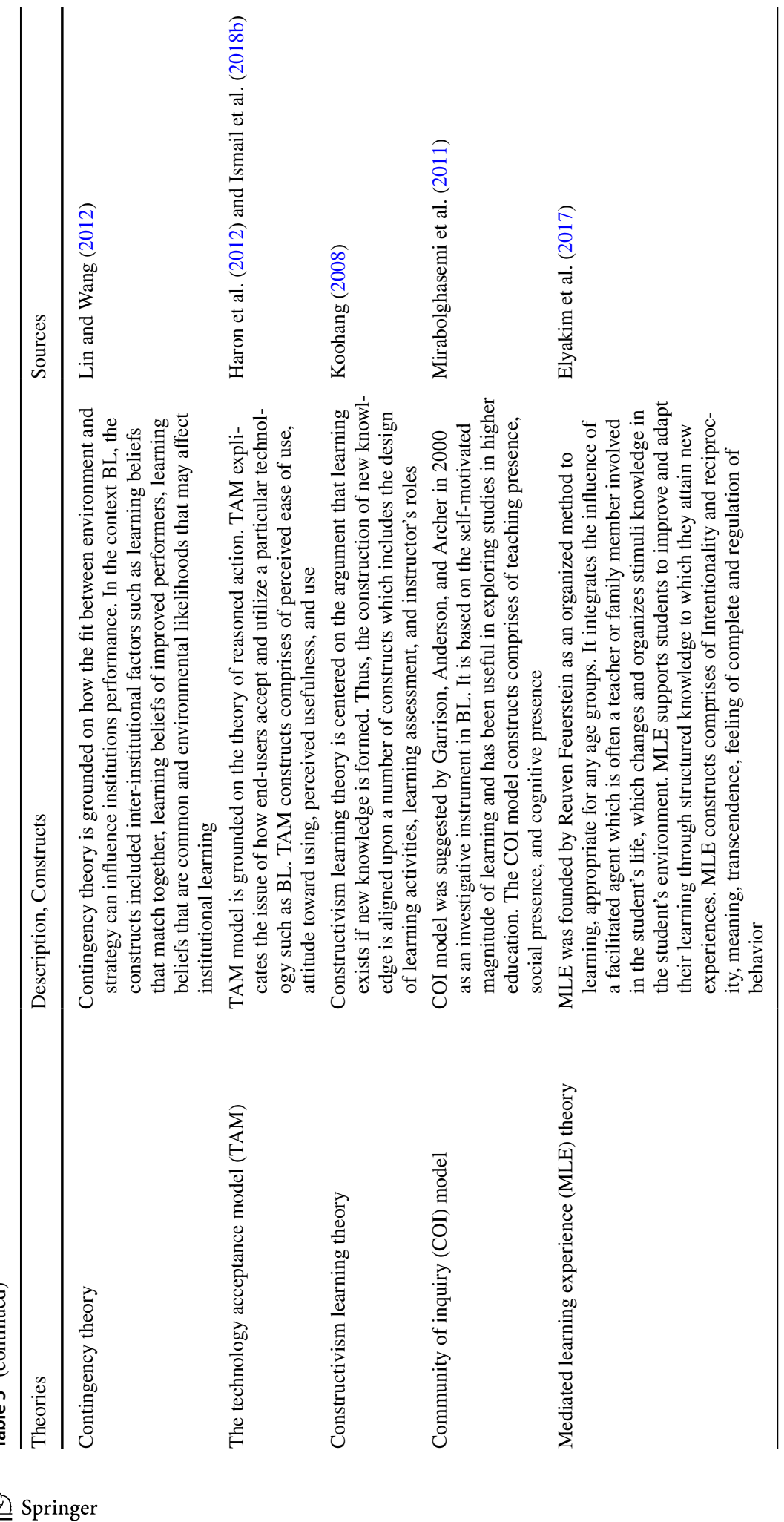




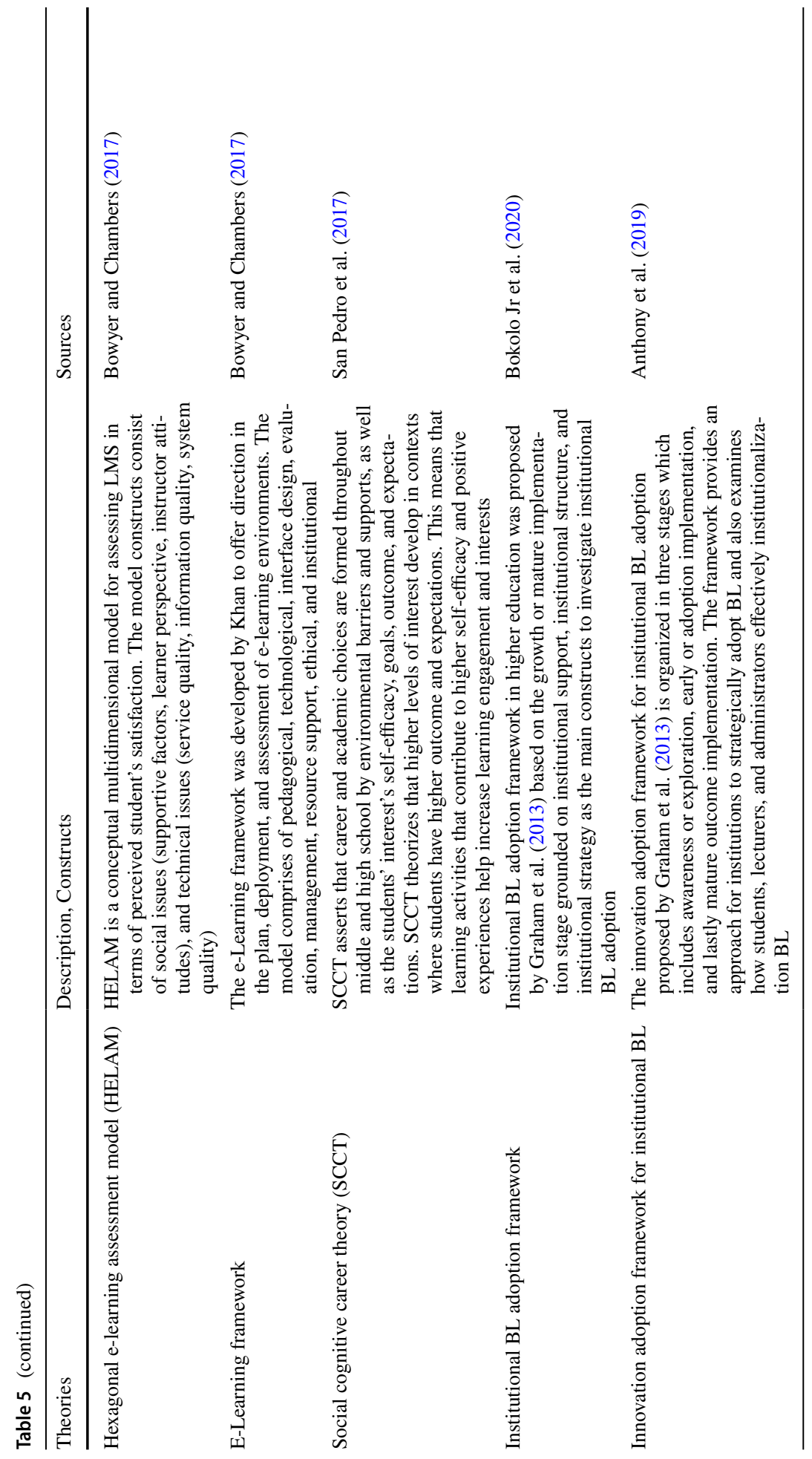




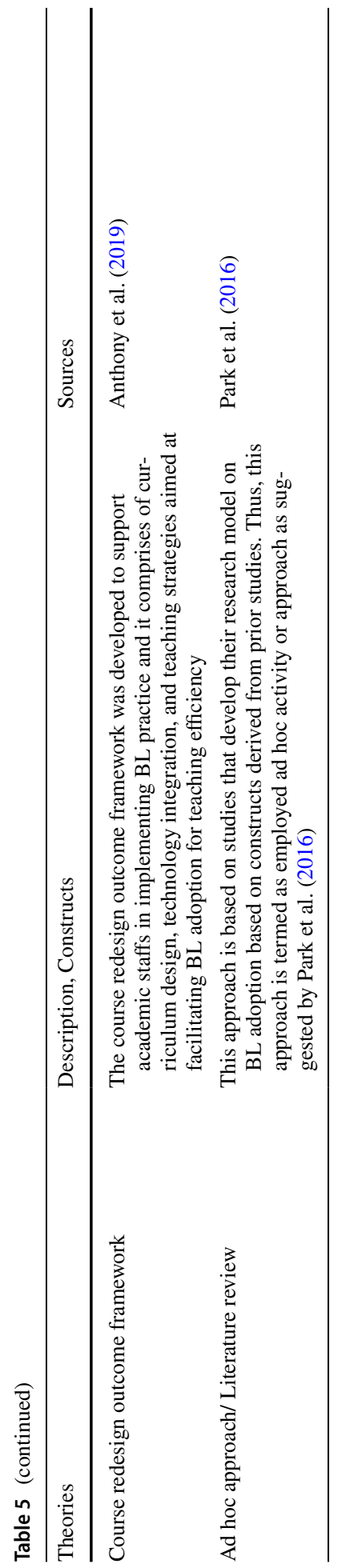

Springer 


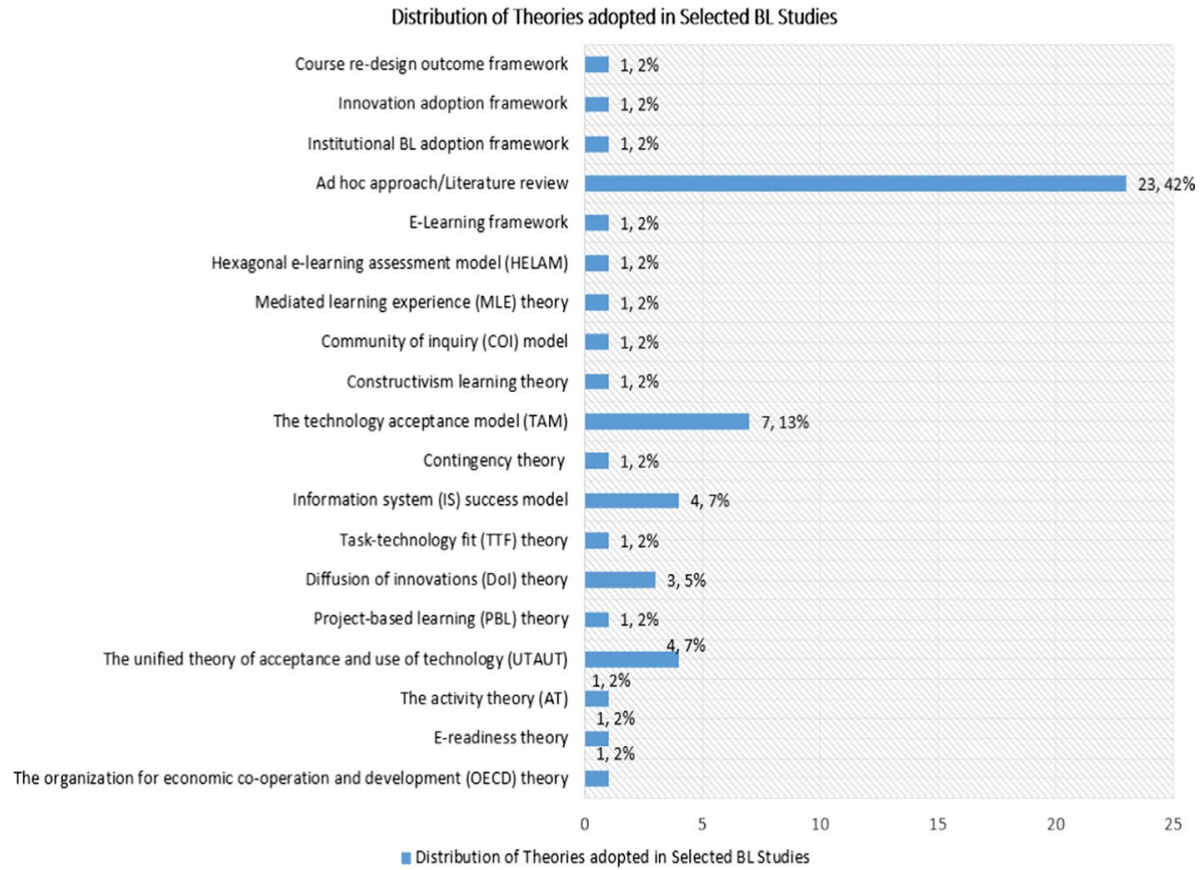

Fig. 12 Distribution of BL studies in terms of adopted theories

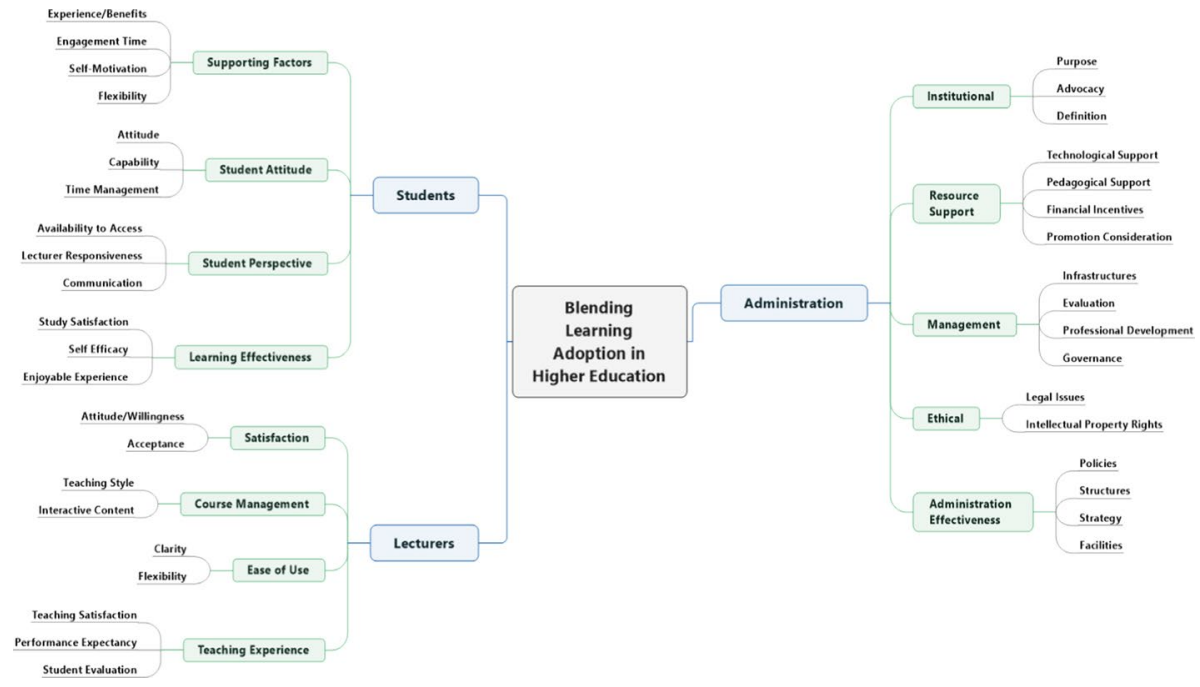

Fig. 13 Constructs and factors related to BL adoption in higher education 
Table 6 BL adoption constructs and factors for students

Level
Students
Refers to learners or scholars that are enrolled
to learn. These students are influences by their
behaviors towards attaining learning goals

Constructs/Factors

\section{Supportive factors}

This variable is influenced by the communication and interaction between students and among the lecture based on the experience/benefit, engagement time, self-motivation, and flexibility of the students towards BL adoption

In education domain experience refers to the student's prior knowledge of technological innovations, as well as the skills acquired by the student from such experience (Machado 2007). The degree of experience in IT can encourage or discourage students from adopting BL. As a result, students' prior know-how may impact their ability to towards BL (Baragash and Al-Samarraie 2018b), apparently due to the need for them to reflect upon the learning process

Student engagement in learning refers to the time and effort student devote in BL activities, where student engagement relates to student's willingness, passion and interest to learn (Barnard et al. 2009)

For self-motivation, if students have interest in what they are studying, they are more likely to concentrate in the learning process (Poon 2014; Ghazal et al. 2018)

It also involves the flexibility of the learning environment and the capability to manage learning pace which is aligned to the ease with which students can respond to BL (Ozkan and Koseler 2009; PadillaMeléndez et al. 2013)

\section{Student Attitude}

Attitude is involves the feeling and perception of the students towards BL in relation to the predictable advantages that can be acquired by the student from BL environment. This construct comprises of attitude, capability, and time management

In BL the attitude of students is determined based on their impression of interaction and engagement in F2F and online activities (Lin and Wang 2012; Poon 2014). Students who have positive attitudes toward IT usage are more enthusiastic to changes in learning environment (Machado 2007)

As the concept of BL is relatively new to students, the capability of the students in using IT in today's classroom where IT skills are needed to achieve an improved learning experience to ensure that the students are capable of learning with technology effectively (Baragash and Al-Samarraie 2018b)

Students are faced with issues related to proper time management especially in a BL approach where online tasks are necessary to be completed alongside F2F classes (Lin and Wang 2012), thus students should be prepared to dedicate extra time in BL (Anthony et al. 2019) 
Table 6 (continued)

Student's perspective of BL is determined by the level of lecturer responsiveness, communication and availability to access

For effective BL adoption, there should be available internet connections provided for educational use, while instantaneously providing 24/7 learning resources to students (Prasad et al. 2018). Students should be able to easily gain access, view and download course module information during classes (Anthony et al. 2019)

Student rates lecturer teaching in BL based on his/her online responsiveness which refers to the lecturer's prompt answer to online requests and problems. Lecturer's feedback is an important factor in promoting positive BL experience (Ghazal et al. 2018)

Communication provides feedback that may arise from the interaction between classmates in BL environment that offers opportunities for students to improve their learning outcome (Padilla-Meléndez et al. 2013)

\section{Learning Effectiveness}

This is the outcome expectation that describes the extent to which BL has enhanced students' learning. The learning effectiveness is measured based on study satisfaction, self-efficacy, and enjoyable experience

Satisfaction refers to the student's perceptions of the degree to which BL meets their learning expectations and needs (Dakduk et al. 2018). Student satisfaction is an essential factor to measure the quality of BL because of its relation to rates of completion and student success (Anthony et al. 2019)

Self-efficacy refers to the student's judgments of his/ her capabilities to execute and organize activities required to achieve improved learning performances. Self-efficacy is an important factor in examining the satisfaction of students towards the belief that he or she can attain enhanced learning (Prasad et al. 2018)

Enjoyable experience is the magnitude to which learning activity of adopting BL is observed to be entertaining in improving BL performance (Poon 2014). Moreover, enjoyable experience relates to students' emotional feedbacks in relation to BL 
Table 7 BL adoption constructs and factors for lecturers

Level
Lecturers
Refers to academic staffs, teachers, trainers or
instructors that disseminate knowledge to
students

Constructs/Factors

\section{a. Satisfaction}

Lecturer satisfaction is a significant key to teaching. Lecturers' satisfaction measures the happiness of the academic staffs in adopting BL for teaching purpose (Dakduk et al. 2018). Thus, the lecturers' satisfaction is measured based on their attitude and acceptance of BL

The lecturers' attitude is an important factor for BL adoption because it entails not only the understanding, knowledge, and significance of BL, but also their aptitude to adapt the theory related-models for teaching (Sun and Qiu 2017)

The acceptance of BL by lecturers is a key factor for BL adoption (Poon 2014). Hence, lecturers' uncertainty or certainty in adopting BL strategies in achieving educational goals defines to a larger extent, their acceptance (Dakduk et al. 2018)

\section{b. Course Management}

Involves employing interactive BL courses content to aid teaching to simplify the teaching style

Teaching style refers to the pattern of teaching behaviors and beliefs demonstrated by lecturer in BL environment (Carbonell et al. 2013). Thus, lecturers with an interactive teaching style may efficiently impact students' participation and involvement in BL environments (Barnard et al. 2009)

BL can create interactive tools that increase students' learning interest. Thus, through BL lecturers can create interesting learning initiatives to improve learning effectiveness (Anthony et al. 2019). Arguably, students are more interested in BL initiatives that offer compelling contents in form of games, visual presentations, and simulations (Dakduk et al. 2018)

\section{c. Ease of Use}

The ease of use of BL means the easiness extent to which the lecturers anticipate the target of BL is of without much effort (Carbonell et al. 2013). It involves how easy it is for the lecturers to provide enthusiastic teaching and assistance to students (Dakduk et al. 2018). It is measured based on clarity and flexibility

BL approach with clarity will help lecturers to be more competent and efficient in their teaching abilities (Barnard et al. 2009; Sun and Qiu 2017). Therefore, it is important that the BL approaches to be employed by lecturers possesses clarity for easy usage and not much technological complex (Anthony et al. 2019)

Flexibility of use refers to the degree to which BL adoption will require less skills and effort for the lecturer. Flexibility is based on the easiness of actual adoption of BL as perceived by less-experienced lecturers (Baragash and Al-Samarraie 2018a). Also, flexible accessibility operation of course modules anytime and anywhere for lecturers in order to achieve clarity for successful adoption of BL 
Table 7 (continued)

\begin{tabular}{ll}
\hline Level & Constructs/Factors \\
\hline d. Teaching Effectiveness & Teaching effectiveness focus on how the lecturer can \\
improve student learning impact in BL. Teaching effec- & tiveness is measured based on the teaching satisfac- \\
tion, performance expectancy, and student evaluation & Teaching satisfaction can be measured based on the \\
lecturers' level of fulfillment in relation to the design & of methods and curriculum, presentation of course \\
objectives, course delivery and students' performance & (Dakduk et al. 2018). Teaching satisfaction is depend- \\
ent on lecturers' pedagogy and strategy of teaching \\
(Anthony et al. 2019) \\
Performance expectancy refers to academic develop- \\
ment outcome of the student based on the information \\
and knowledge disseminated by the lecturer during the \\
semester (Anthony et al. 2019) \\
Baragash and Al-Samarraie (2018a) suggested that there \\
is need to evaluate the quality of BL course based on \\
students' perceptions of BL ease of use and usefulness \\
in improving learning outcome. Evaluation can help \\
lecturer to assess students understand and knowledge of \\
course contents (Lin and Wang 2012)
\end{tabular}

and its efficiency in order to improve students' competence. The identified factors can be employed by institutions to assess students, lecturers and administrators' perception towards BL and can be used to inform government policy making regarding BL development. Besides, this study also indicates that the lecturer's attitude, teaching style, and acceptance toward BL are important in motivating the students to adopt BL. The lecturer's attitude toward students and his/her level of responsiveness and communication are important factors that motivate students in BL environment. The findings emphasized the importance of administrative commitment towards BL adoption, showing that the purpose, advocacy and definition initiated towards BL have a strong impact on both learning and teaching effectiveness. The findings provide theoretical support to determine the relationship among the constructs and factors of BL adoption for students, lecturers and administrators (see Fig. 13) towards F2F and online learning.

\subsection{Implications for Methodology}

Based on the TPACK framework, this study provides lecturers with understanding of students' perspective on BL in helping them to reflect on their role in improving their current pedagogy, technological infusion, and syllabus design to enhance student learning and teaching outcome. Decision makers in higher education can utilize findings from this study to improve their understanding of the factors that impacts students, lecturers and administrators' perception towards BL adoption. Respectively, given the different perspectives of students, lecturers and administrators it is mandatory for policy makers in higher education involved in the implementation of BL to deliberate on the perspectives of all stakeholders. Respectively, findings from this study significantly provide an outline for Ministry of 
Table 8 BL adoption constructs and factors for administrators

Level
Administrators
These are the management that set policies and
strategies towards the accreditation, adoption and
recognition of BL activities. They help to actual-
ize BL policies into implementation

Constructs/Factors

\section{a. Institutional}

This construct includes issues concerning the complete design of BL in relation to purpose of $\mathrm{BL}$ policies, methods of advocacy, definition of BL adoption

In terms of purpose, institutions adopting BL should specify the goals they intend to attain. Institutional policies towards BL should encourage lecturers to utilize innovative forms of teaching and learning formats (Porter et al. 2016; Porter and Graham, 2016)

Administrators' advocates provide enthusiasm and cooperation that supports BL adoption to provide the needed structural resource supports for teaching and learning (Dakduk et al. 2018)

Administrators should align their objectives with BL definition in relation to the institution's capacity (Machado 2007). Creating a definition of BL can ease in achieving learning objectives for scheduling lectures (Bokolo Jr et al. 2020), providing students with reliable and clear prospects regarding $\mathrm{BL}$ approach, and developing suitable support initiatives (Poon 2014)

\section{b. Resource Support}

This construct aims to provide resource support to encourage lecturers to become dynamically involved and completely aware of BL initiatives. It comprises technological support, pedagogical support, financial incentives, and promotion consideration

Technological support consists of infrastructure such as wireless, wired network access, other hardware equipment and software components used to ensure that BL can support teaching and learning (Basir et al. 2010)

Administrators need deploy pedagogical support by providing experts that provide guide to lecturers in designing blended course content (Dakduk et al. 2018). Moreover, these experts also help review the designed course and further provide feedback on how lecturers can improve their pedagogies

Administrators can provide financial incentives such as workload reward to encourage lecturers to adopt BL. Moreover, BL adoption remunerations, or funding for BL can be provided to show universities support for BL (Basir et al. 2010)

Equally, tenure and promotion plans should be reviewed to inspire and compensate lecturers adopting BL (Bokolo Jr et al. 2020)

c. Management 
Table 8 (continued)

This construct specifies initiatives to be considered to achieve sustainable, effective use of BL towards supporting institutions realize their established goals in addressing issues relates to infrastructure, professional development, evaluation, and governance

In terms of infrastructure, deployment of required technological infrastructure is essential for effective $\mathrm{BL}$ adoption. Thus, institutions seeking to adopt BL must offer the central technological infrastructure necessary for an effective BL adoption for lecturers and students (Porter et al. 2016; Porter and Graham 2016)

As suggested by Bokolo Jr et al. 2020 BL adoption needs to be periodically evaluated to ascertain the strength and weakness. The evaluation procedure measures students learning experiences and lecturers teaching satisfaction towards BL as quality assurance initiative that provides continuous feedback for BL improvement

Professional development is an important factor that promote BL adoption. Hence, administrators should organize workshops to enhance lecturers' development of pedagogical strategies in fostering BL teaching in improving technology-mediatedteaching of students (Porter and Graham 2016)

Administrators should have a governance procedure to help determine who approves BL courses to be taught in the institution such as the ration of 20-80, 30-70, or 40-60 for F2F and e-learning (Porter et al. 2016)

\section{d. Ethical}

This construct encompasses legal matters related to intellectual property (IP) right. Thus, BL policies initiated should clearly state regulation and rules relating to ownership of course materials, editing and rights privileges, circulation of learning materials designed by lecturers (Bokolo Jr et al. 2020)

\section{e. Administration Effectiveness}

$\mathrm{BL}$ is effective when institutions are committed to improve the quality of the student learning and lecturers teaching experience in a cost-effective manner (Porter et al. 2016). Thus, administration should provide clear policies, better structure, accessible facilities and a more organized strategies for the planning of BL implementation. Thus, it is a required for administration to initiate agenda to meet the strategic goal of redesigning BL courses (Porter and Graham 2016) 


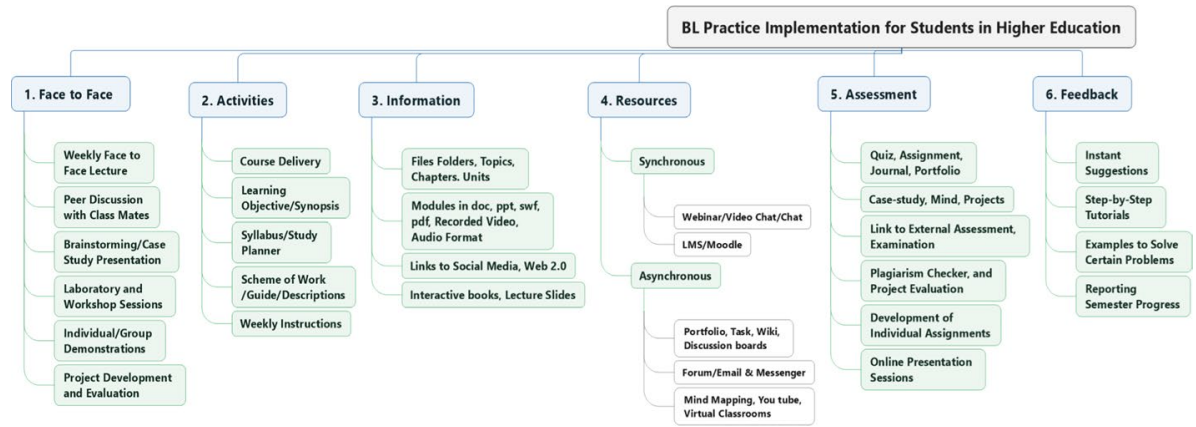

Fig. 14 BL practice implementation for students in higher education

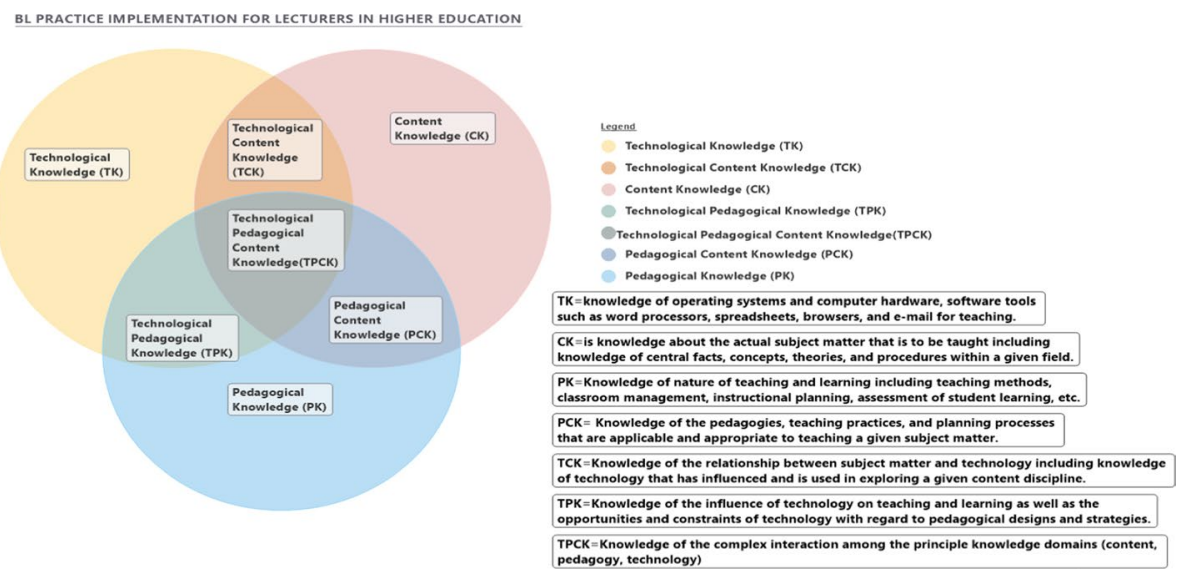

Fig. 15 BL practice implementation for lecturers in higher education

Education across the world towards fostering BL as a teaching and learning approach for academic staffs in higher education. The BL practices for students (see Fig. 14) and strategies to be implemented by lecturers (see Fig. 15) can be integrated to the existing pedagogical polices to improve the significance of $\mathrm{BL}$ as one of the methods in learning and teaching. For universities and academicians, findings from this study suggest that BL serves as a substitute to learning and teaching from the traditional perspective to enhance the quality of teaching and learning of students in achieving better performance.

\subsection{Implications for Pedagogical Practice}

This study contributes to the acknowledgment of BL as a medium to support teaching and learning approach. The findings describing how BL practice can be implemented by students as seen in Sect. 4.6 (Fig. 14). Practically, findings from this study can be useful in the preparation of the best practice to support lecturers in teaching and implementing inventive approaches that promotes BL to enhance teaching and learning outcomes to be used as the reference for the arranging methodologies to embrace $\mathrm{BL}$ in higher education. Findings from 
Table 9 Description of BL learning practice implementation for students in higher education

\begin{tabular}{|c|c|}
\hline BL practice & Description \\
\hline Face to face & $\begin{array}{l}\text { This is the offline learning which comprises of discussions and physical skill practices initi- } \\
\text { ated by the lecturer to examine the learning quality of the students based on class lectures } \\
\text { (Akkoyunlu and Y1lmaz-Soylu 2008; Sun and Qiu 2017), individual and group discussion, } \\
\text { lab sessions, presentation activities, and evaluations (Baragash and Al-Samarraie 2018a; } \\
\text { Ghazal et al. 2018) }\end{array}$ \\
\hline
\end{tabular}

Activities This phase refers to group of features in an LMS that provides a platform for student to interact with the lecture and other students based on forum, assignments, chat, external tools, glossary, lessons, workshop, survey, wiki, etc. (Kaur 2013; Park et al. 2016)

Information In BL information refers to an item that lecturers can add to online course platform such as LMS to provide extra information or links to support learning (Machado 2007; Lin and Wang 2012). It ranges from timetable schedule, course overview, course description, course status, latest course news, upcoming events, online users, recent activities, collective activities, etc. (Padilla-Meléndez et al. 2013)

Resources This is an item that a lecturer can utilize to facilitate learning such as a link or file. LMS such as Moodle offers a several resource types which enables lecturers to add courses, such as a page, study file, folder, and URL (Edward et al. 2018). Moreover, resources comprise of synchronous and asynchronous, where synchronously, can be in a group chat, whereas asynchronous could be in a forum to which students post responses (Lin and Wang 2012; Baragash and Al-Samarraie 2018b)

Assessment Generally, refers to a systematic means for measuring development and learning of students. In BL assessments can either be summative or formative, where formative assessments are conducted once students finish reading the course chapter, whereas summative assessments are conducted at the end of semester (Koohang 2008). Results from assessments help students in actualizing personal goals and making decisions for improvement (Sun and Qiu 2017)

Feedback Refers to the qualitative view or comment from both students and lecturers based on course content and student's performance (Ginns and Ellis 2007; Sun and Qiu 2017). It supports students' development in learning and provides opportunity to reduce the gap between present and preferred performance. Besides. lecturers offer feedback on students' performance and provide answers to queries or problems from students (Padilla-Meléndez et al. 2013)

this study indicate that BL practices derived from the literature which comprises of face-toface, activities, information, resources, assessment, and feedback to be deployed by educators to design suitable learning policies in order to support students towards improving learning. These findings provide guidelines on the design and implementation of BL practice. This study suggests that for BL practice to be successfully implemented the decision of lecturers are determined by the ease with which online course services are managed. Thus, the availability of computer hardware and software resources, pedagogical support, financial support, and promotion consideration should be provided by institutions management. For administrators this study provides a policy roadmap to adopt BL in higher education.

\section{Conclusion, Limitations, and Future Works}

Review of prior studies on BL offer valuable insight regarding research related to BL practice in higher education. Nonetheless, these review studies ignored examining BL adoption and implementation in regard to students, lecturers and administrators simultaneously. Accordingly, this study conducted a systematic literature review for prior BL adoption model proposed related to theories employed in the model to investigate BL adoption in higher education. This study also identified the constructs and factors that influence students, lecturers 
Table 10 Description of BL teaching practice implementation for lecturers in higher education

BL Practice Description

Technology Knowledge (TK)

Pedagogical Knowledge (PK)

Content Knowledge (CK)

Pedagogical Content Knowledge (PCK)

Technological Content Knowledge (TCK)

Technological Pedagogical Knowledge (TPK)

Technological Pedagogical Content Knowledge (TPCK)
In relation to $\mathrm{BL}$, TK includes the lecturers' knowledge of operating systems, software, and hardware, and the capability to utilize teaching software applications such as Microsoft word, PowerPoint, Excel spreadsheets, creating of documents, use of browsers, and e-mail for teaching (Graham et al. 2009; Koehler and Mishra 2009; Schmidt et al. 2009)

PK involves knowledge about the practices or procedures of teaching and learning and how it links to educational aims and objectives (Wang et al. 2004). Thus, PK involved issues related to student learning, managing classroom, developing and implementing lesson plan. It also entails knowledge steps to be followed in the classroom based on the type of students and strategies for assessing student learning (Koehler and Mishra 2009)

CK is knowledge relating to fundamental theories, concepts, facts, and procedures of the actual subject matter that is to be taught or learned (Sahin 2011). Thus, it includes knowledge of how to organize and connect course content ideas for BL (Koehler and Mishra 2009)

PCK entails the intersection of pedagogy and content. Therefore, it represents the integration of pedagogy and content by the lecturer into an understanding of how the subject matter are prearranged, adapted, and represented for teaching students in a BL environment (Koehler and Mishra 2009; Schmidt et al. 2009)

TCK is knowledge relating to the method in which content and technology for teaching are equally related (Koehler and Mishra 2009). In BL, TCK entails how technology is used by lectures to representation course contents to students (Graham et al. 2009)

TPK is lecturers' knowledge of the current modules, and capabilities of different technologies that can be deployed for BL teaching (Wang et al. 2004). It also involves lecturers' knowing how teaching with a particular technology might change the learning outcome (Koehler and Mishra 2009)

TPACK is the combination of good teaching with technology that involves lecturer's having knowledge of the course theories using technologies and pedagogical methods (Koehler and Mishra 2009). Thus, it involves the usage of technologies in a productive way to teach course content in BL environment (Wang et al. 2004)

and administration towards adopting BL studies and lastly derived the practices involved for BL implementation for students and lecturers in higher education with the aim of providing meta-analysis of the current studies and to present the implications from the review. Respectively, this paper extends the body of knowledge in BL studies by presenting 7 new findings. First, the review reveal that ad hoc approach is the most employed method by prior studies in developing research model to investigate BL adoption in higher education, followed by TAM, and then IS success model, then is UTAUT, and lastly DoI theory. 
Secondly, findings show that questionnaire surveys were the most employed research methods for data collection utilized by prior BL studies in higher education. Third, the findings reveal that BL model adoption studies were carry out in Malaysia and USA, this is followed by Australia, UK, Canada, respectively among the other countries. Fourth, most of the BL studies were recurrently conducted towards examining BL in students' context, followed by lecturers' context, correspondingly among the other contexts. Fifth, with regard to publication year, BL studies have experienced vast attraction over the years (2016 to 2019) from many academicians who contributed to investigating BL adoption and implementation in higher educational context, where our findings observed an increase of 19 publications in 2018 (see Fig. 4) representing the highest frequency of the total studies. Sixth, this review also presents 51 prior studies that developed model relating to the adoption of $\mathrm{BL}$ in higher educational domain and further identify the constructs/factors that influence the perception of students, lecturers, and administration readiness towards BL adoption. Seventh, findings from this review present the BL practice to be implemented by students and lecturers in higher education. To that end, the identified constructs/factors that influence BL adoption and the derived BL practices implementation can be used to conceptualize and develop a model to examine student, lecturers, and administrators concurrently towards BL adoption and implementation in higher education.

Despite the aforementioned contributions, this study has a few limitations. First, the reviewed BL studies comprises of studies related to BL adoption and implementation approaches, models, and frameworks. BL readiness and effectiveness were not investigated in this current study. Secondly, this study mainly focused on popular online databases for collecting articles (i.e., ScienceDirect, Sage, Emerald, Inderscience, Wiley, Google Scholar, Springer, Taylor \& Francis, and IEEE). Given that, the databases may not provide all relevant studies published on BL adoption and implementation. Thirdly, no theoretical model was proposed with hypotheses for further validation. Future studies could examine BL readiness and effectiveness from student, lecturers, and administrator's perspective by developing a research model with hypotheses. The model will be evaluated using survey questionnaire since it's the most widely employed methodology as seen in Fig. 5 and 8. Further research could also extent this study by including more BL studies from other online libraries which includes Web of Science, Scopus, etc. to investigate BL in its broad sense and how it affects students, lecturers and administration in a particular country or region.

Funding Open Access funding provided by NTNU Norwegian University of Science and Technology (incl St. Olavs Hospital - Trondheim University Hospital) This study was supported by Universiti Malaysia Pahang Malaysia Grant No. RDU180702.

\section{Compliance with Ethical Standards}

Conflict of interest The authors declare that they have no conflict of interest.

Open Access This article is licensed under a Creative Commons Attribution 4.0 International License, which permits use, sharing, adaptation, distribution and reproduction in any medium or format, as long as you give appropriate credit to the original author(s) and the source, provide a link to the Creative Commons licence, and indicate if changes were made. The images or other third party material in this article are included in the article's Creative Commons licence, unless indicated otherwise in a credit line to the material. If material is not included in the article's Creative Commons licence and your intended use is not permitted by statutory regulation or exceeds the permitted use, you will need to obtain permission directly from the copyright holder. To view a copy of this licence, visit http://creativecommons.org/licenses/by/4.0/.

\section{Appendix}

See Table 11. 
Table 11 Results of quality assessment

\begin{tabular}{|c|c|c|c|c|c|c|c|c|c|c|c|}
\hline Study & Q1 & Q2 & Q3 & Q4 & Q5 & Q6 & Q7 & Q8 & Q9 & Q10 & Percentage $(\%)$ \\
\hline S1 & 1 & 1 & 1 & 1 & 1 & 0 & 0 & 0 & 0.5 & 1 & 70 \\
\hline S2 & 1 & 0 & 1 & 1 & 1 & 1 & 1 & 0 & 1 & 1 & 80 \\
\hline S3 & 1 & 1 & 1 & 1 & 1 & 0 & 0 & 0 & 0.5 & 0.5 & 60 \\
\hline S4 & 1 & 0 & 1 & 1 & 1 & 1 & 1 & 1 & 1 & 0.5 & 85 \\
\hline S5 & 1 & 0 & 1 & 1 & 1 & 1 & 1 & 1 & 1 & 1 & 90 \\
\hline S6 & 1 & 0 & 1 & 1 & 1 & 0 & 0 & 0 & 0.5 & 1 & 55 \\
\hline S7 & 1 & 1 & 1 & 1 & 0 & 1 & 0 & 1 & 1 & 1 & 80 \\
\hline S8 & 1 & 0 & 1 & 1 & 1 & 1 & 0 & 1 & 1 & 1 & 80 \\
\hline S9 & 1 & 0 & 1 & 1 & 0.5 & 1 & 0 & 1 & 0.5 & 0.5 & 65 \\
\hline S10 & 1 & 0 & 1 & 1 & 0.5 & 0.5 & 0 & 1 & 0.5 & 0.5 & 60 \\
\hline S11 & 1 & 0 & 1 & 1 & 0 & 1 & 0 & 1 & 1 & 0.5 & 65 \\
\hline S12 & 1 & 1 & 1 & 1 & 1 & 0 & 0 & 0 & 0.5 & 1 & 65 \\
\hline S13 & 1 & 0 & 1 & 1 & 1 & 1 & 1 & 1 & 1 & 1 & 90 \\
\hline S14 & 1 & 0 & 1 & 1 & 1 & 1 & 1 & 1 & 1 & 0.5 & 85 \\
\hline S15 & 1 & 1 & 0 & 1 & 1 & 1 & 1 & 1 & 1 & 0.5 & 85 \\
\hline S16 & 1 & 0 & 1 & 1 & 1 & 1 & 1 & 1 & 1 & 0 & 80 \\
\hline S17 & 1 & 0 & 1 & 1 & 1 & 0 & 0 & 0 & 1 & 1 & 60 \\
\hline S18 & 1 & 1 & 0 & 1 & 1 & 0 & 0 & 0 & 1 & 1 & 60 \\
\hline S19 & 1 & 1 & 0 & 1 & 1 & 1 & 1 & 1 & 1 & 0.5 & 85 \\
\hline S20 & 1 & 0 & 1 & 1 & 1 & 1 & 1 & 1 & 1 & 1 & 90 \\
\hline S21 & 1 & 0 & 1 & 1 & 1 & 1 & 1 & 1 & 1 & 0.5 & 85 \\
\hline S22 & 1 & 1 & 1 & 1 & 1 & 0 & 0 & 0 & 1 & 1 & 70 \\
\hline S23 & 1 & 1 & 0 & 1 & 1 & 1 & 1 & 1 & 1 & 0.5 & 85 \\
\hline S24 & 1 & 0 & 1 & 1 & 1 & 0 & 0 & 0 & 1 & 1 & 60 \\
\hline S25 & 1 & 1 & 0 & 1 & 1 & 0 & 0 & 0 & 1 & 1 & 60 \\
\hline S26 & 1 & 0 & 1 & 1 & 1 & 1 & 1 & 1 & 1 & 0.5 & 85 \\
\hline S27 & 1 & 1 & 1 & 1 & 1 & 1 & 1 & 1 & 1 & 0.5 & 95 \\
\hline S28 & 1 & 0 & 1 & 1 & 1 & 1 & 1 & 1 & 1 & 0.5 & 85 \\
\hline S29 & 1 & 1 & 1 & 1 & 1 & 1 & 1 & 1 & 1 & 0.5 & 95 \\
\hline S30 & 1 & 1 & 0 & 1 & 1 & 1 & 1 & 1 & 1 & 0.5 & 85 \\
\hline S31 & 1 & 1 & 1 & 1 & 1 & 0 & 0 & 0 & 1 & 1 & 70 \\
\hline S32 & 1 & 0 & 1 & 1 & 1 & 0 & 0 & 0 & 1 & 1 & 60 \\
\hline S33 & 1 & 0.5 & 1 & 1 & 1 & 1 & 1 & 1 & 1 & 1 & 95 \\
\hline S34 & 1 & 0 & 1 & 1 & 1 & 1 & 1 & 1 & 1 & 0.5 & 85 \\
\hline S35 & 1 & 0 & 1 & 1 & 1 & 1 & 1 & 1 & 1 & 0.5 & 85 \\
\hline S36 & 1 & 0 & 1 & 1 & 1 & 1 & 1 & 1 & 1 & 0.5 & 85 \\
\hline S37 & 1 & 1 & 0 & 1 & 1 & 1 & 1 & 1 & 1 & 0 & 80 \\
\hline S38 & 1 & 0 & 1 & 1 & 1 & 1 & 1 & 1 & 1 & 0 & 80 \\
\hline S39 & 1 & 1 & 0.5 & 1 & 1 & 0 & 0 & 0 & 0 & 0.5 & 50 \\
\hline $\mathrm{S} 40$ & 1 & 1 & 0 & 1 & 1 & 1 & 1 & 1 & 0.5 & 0 & 75 \\
\hline S41 & 1 & 1 & 1 & 1 & 1 & 0 & 0 & 0 & 0 & 0.5 & 55 \\
\hline S42 & 1 & 1 & 0 & 1 & 1 & 1 & 1 & 1 & 1 & 0.5 & 85 \\
\hline S43 & 1 & 0.5 & 1 & 1 & 1 & 1 & 1 & 1 & 1 & 0 & 85 \\
\hline S44 & 1 & 0.5 & 1 & 1 & 1 & 1 & 1 & 1 & 1 & 0 & 85 \\
\hline
\end{tabular}


Table 11 (continued)

\begin{tabular}{|c|c|c|c|c|c|c|c|c|c|c|c|}
\hline Study & Q1 & Q2 & Q3 & Q4 & Q5 & Q6 & Q7 & Q8 & Q9 & Q10 & Percentage (\%) \\
\hline S45 & 1 & 0.5 & 0.5 & 1 & 1 & 1 & 1 & 1 & 1 & 0 & 80 \\
\hline S46 & 1 & 0.5 & 0.5 & 1 & 1 & 1 & 1 & 1 & 1 & 1 & 90 \\
\hline S47 & 1 & 0.5 & 1 & 1 & 1 & 1 & 1 & 1 & 1 & 1 & 95 \\
\hline S48 & 1 & 1 & 0.5 & 1 & 1 & 0 & 0 & 0 & 0 & 0.5 & 50 \\
\hline S49 & 1 & 0 & 1 & 1 & 1 & 1 & 1 & 1 & 0.5 & 0.5 & 80 \\
\hline S50 & 1 & 0 & 1 & 1 & 1 & 1 & 1 & 1 & 0.5 & 0 & 75 \\
\hline S51 & 1 & 0.5 & 0.5 & 1 & 1 & 1 & 1 & 1 & 0.5 & 0.5 & 80 \\
\hline S52 & 1 & 0.5 & 0 & 1 & 1 & 1 & 1 & 1 & 0.5 & 0 & 70 \\
\hline S53 & 1 & 0 & 1 & 1 & 1 & 1 & 1 & 1 & 1 & 0 & 80 \\
\hline S54 & 1 & 0 & 1 & 1 & 1 & 1 & 1 & 1 & 1 & 1 & 90 \\
\hline S55 & 1 & 0 & 1 & 1 & 1 & 1 & 1 & 1 & 1 & 0 & 80 \\
\hline S56 & 1 & 0 & 1 & 1 & 1 & 1 & 1 & 1 & 1 & 1 & 90 \\
\hline S57 & 1 & 0 & 1 & 1 & 1 & 1 & 1 & 1 & 1 & 0 & 80 \\
\hline S58 & 1 & 0 & 1 & 1 & 1 & 1 & 1 & 1 & 1 & 0 & 80 \\
\hline S59 & 1 & 0 & 1 & 1 & 1 & 1 & 1 & 1 & 1 & 0 & 80 \\
\hline S60 & 1 & 0 & 1 & 1 & 1 & 1 & 1 & 1 & 1 & 0 & 80 \\
\hline S61 & 1 & 1 & 1 & 1 & 1 & 0 & 0 & 0 & 0 & 0 & 50 \\
\hline S62 & 1 & 0 & 1 & 1 & 1 & 1 & 1 & 1 & 0.5 & 0 & 75 \\
\hline S63 & 1 & 0.5 & 1 & 1 & 1 & 1 & 1 & 1 & 1 & 0.5 & 90 \\
\hline S64 & 1 & 1 & 0.5 & 1 & 1 & 1 & 1 & 1 & 1 & 1 & 95 \\
\hline S65 & 1 & 1 & 0.5 & 1 & 1 & 0 & 0 & 0 & 0.5 & 0.5 & 55 \\
\hline S66 & 1 & 0 & 1 & 1 & 1 & 1 & 1 & 1 & 1 & 0 & 80 \\
\hline S67 & 1 & 1 & 1 & 1 & 1 & 0.5 & 0.5 & 0.5 & 0.5 & 0 & 70 \\
\hline S68 & 1 & 0 & 1 & 1 & 1 & 1 & 1 & 1 & 1 & 0 & 80 \\
\hline S69 & 1 & 0 & 1 & 1 & 1 & 1 & 1 & 1 & 1 & 0.5 & 85 \\
\hline S70 & 1 & 1 & 1 & 1 & 1 & 0 & 0 & 0 & 0.5 & 0 & 55 \\
\hline S71 & 1 & 0 & 1 & 1 & 1 & 1 & 1 & 1 & 1 & 0 & 80 \\
\hline S72 & 1 & 0 & 1 & 1 & 1 & 1 & 1 & 1 & 1 & 1 & 90 \\
\hline S73 & 1 & 1 & 0 & 1 & 1 & 1 & 1 & 1 & 1 & 0 & 80 \\
\hline S74 & 1 & 1 & 1 & 1 & 1 & 1 & 1 & 1 & 1 & 0 & 90 \\
\hline S75 & 1 & 1 & 1 & 1 & 1 & 1 & 1 & 1 & 1 & 0.5 & 95 \\
\hline S76 & 1 & 0.5 & 0.5 & 1 & 1 & 1 & 1 & 1 & 1 & 0 & 80 \\
\hline S77 & 1 & 1 & 0 & 1 & 1 & 1 & 1 & 1 & 1 & 0 & 80 \\
\hline S78 & 1 & 0 & 1 & 1 & 1 & 1 & 1 & 1 & 1 & 0 & 80 \\
\hline S79 & 1 & 1 & 0 & 1 & 1 & 1 & 1 & 1 & 1 & 0 & 80 \\
\hline S80 & 1 & 1 & 0 & 1 & 1 & 0 & 0 & 0 & 1 & 0 & 50 \\
\hline S81 & 1 & 1 & 0 & 1 & 1 & 1 & 1 & 1 & 1 & 0 & 80 \\
\hline S82 & 1 & 1 & 0 & 1 & 1 & 1 & 1 & 1 & 1 & 0 & 80 \\
\hline S83 & 1 & 1 & 0 & 1 & 1 & 1 & 1 & 1 & 1 & 0 & 80 \\
\hline S84 & 1 & 0 & 1 & 1 & 1 & 1 & 1 & 1 & 1 & 1 & 90 \\
\hline S85 & 1 & 0 & 1 & 1 & 1 & 1 & 1 & 1 & 1 & 0.5 & 85 \\
\hline S86 & 1 & 1 & 1 & 1 & 1 & 1 & 1 & 1 & 1 & 0.5 & 95 \\
\hline S87 & 1 & 0 & 1 & 1 & 1 & 1 & 1 & 1 & 1 & 0.5 & 85 \\
\hline S88 & 1 & 1 & 1 & 1 & 1 & 1 & 1 & 1 & 1 & 0.5 & 95 \\
\hline
\end{tabular}


Table 11 (continued)

\begin{tabular}{llllllllllll}
\hline Study & Q1 & Q2 & Q3 & Q4 & Q5 & Q6 & Q7 & Q8 & Q9 & Q10 & Percentage (\%) \\
\hline S89 & 1 & 1 & 0 & 1 & 1 & 1 & 1 & 1 & 1 & 0.5 & 85 \\
S90 & 1 & 1 & 1 & 1 & 1 & 0 & 0 & 0 & 1 & 1 & 70 \\
S91 & 1 & 0 & 1 & 1 & 1 & 0.5 & 0 & 0.5 & 1 & 1 & 70 \\
S92 & 1 & 0.5 & 1 & 1 & 1 & 1 & 1 & 1 & 1 & 0.5 & 90 \\
S93 & 1 & 1 & 0.5 & 1 & 1 & 1 & 1 & 1 & 1 & 1 & 95 \\
S94 & 1 & 0.5 & 1 & 1 & 1 & 1 & 1 & 1 & 1 & 0.5 & 90 \\
\hline
\end{tabular}

\section{References}

Aguti, B., Walters, R., \& Wills, G. (2013). A framework for evaluating the effectiveness of blended e-learning within universities. In Society for Information Technology \& Teacher Education International Conference, 1982-1987.

Aguti, B., Wills, G. B., \& Walters, R. J. (2014). An evaluation of the factors that impact on the effectiveness of blended e-learning within universities. In International Conference on Information Society (i-Society), 117-121.

Ahmed, H. M. S. (2010). Hybrid E-Learning acceptance model: Learner perceptions. Decision Sciences Journal of Innovative Education, 8(2), 313-346.

Akkoyunlu, B., \& Yilmaz-Soylu, M. (2008). Development of a scale on learners' views on blended learning and its implementation process. The Internet and Higher Education, 11(1), 26-32.

Al-Emran, M., Mezhuyev, V., \& Kamaludin, A. (2018). Technology acceptance model in M-learning context: A systematic review. Computers and Education, 125, 389-412.

Al-Rahmi, W. M., Alias, N., Othman, M. S., Alzahrani, A. I., Alfarraj, O., Saged, A. A., et al. (2018). Use of E-Learning by University Students in Malaysian Higher Educational Institutions: A Case in UniversitiTeknologi Malaysia. IEEE Access, 6, 14268-14276.

Al-shami, S. A., Aziz, H., \& Rashid, N. (2018). The adoption of MOOC utilization among undergraduate students in UniversitiTeknikal Malaysia Melaka (UTEM). Journal of Fundamental and Applied Sciences, 10(6S), 2634-2654.

Alhabeeb, A., \& Rowley, J. (2018). E-learning critical success factors: Comparing perspectives from academic staff and students. Computers and Education, 127, 1-12.

Anthony, B., Kamaludin, A., Romli, A., Raffei, A. F. M., Abdullah, A., Ming, G. L., et al. (2019). Exploring the role of blended learning for teaching and learning effectiveness in institutions of higher learning: An empirical investigation. Education and Information Technologies, 24(6), 3433-3466.

Anthony, B, Majid, M. A., \& Romli, A. (2017a). Sustainable adoption and implementation in collaborative enterprise: A systematic literature review. Journal of Theoretical \& Applied Information Technology, 95(9), 1875-1915.

Anthony, B., Majid, M. A., \& Romli, A. (2017b). Green information technology system practice for sustainable collaborative enterprise: A structural literature review. International Journal of Sustainable Society, 9(3), 242-272.

Azizan, F. Z. (2010). Blended learning in higher education institution in Malaysia. In Proceedings of regional conference on knowledge integration in ICT (pp. 454-466).

Bailey, M., Ifenthaler, D., Gosper, M., Kretzschmar, M., \& Ware, C. (2015). The changing importance of factors influencing students' choice of study mode. Technology, Knowledge and Learning, 20(2), 169-184.

Baragash, R. S., \& Al-Samarraie, H. (2018a). An empirical study of the impact of multiple modes of delivery on student learning in a blended course. The Reference Librarian, 59(3), 149-162.

Baragash, R. S., \& Al-Samarraie, H. (2018b). Blended learning: Investigating the influence of engagement in multiple learning delivery modes on students' performance. Telematics and Informatics, 35(7), 2082-2098.

Barnard, L., Lan, W. Y., To, Y. M., Paton, V. O., \& Lai, S. L. (2009). Measuring self-regulation in online and blended learning environments. The Internet and Higher Education, 12(1), 1-6.

Basir, H. M., Ahmad, A., \& Noor, N. L. M. (2010). Institutional strategy for effective blended e-learning: HCI perspective of sustainable embedding. $i$-USEr (pp. 71-76). 
Bervell, B., \& Umar, I. N. (2018). Blended learning or face-to-face? Does Tutor anxiety prevent the adoption of Learning Management Systems for distance education in Ghana? Open Learning: The Journal of Open, Distance and e-Learning, 35(2), 159-177.

Bokolo, A., Jr., Kamaludin, A., Romli, A., Mat Raffei, A. F., A/L Eh Phon, D. N., Abdullah, A., et al. (2020). A managerial perspective on institutions' administration readiness to diffuse blended learning in higher education: Concept and evidence. Journal of Research on Technology in Education, 52(1), 37-64.

Bowyer, J., \& Chambers, L. (2017). Evaluating blended learning: Bringing the elements together. Research Matters: A Cambridge Assessment Publication, 23, 17-26.

Brahim, M., \& Mohamad, M. (2018). Awareness, Readiness and acceptance of the Students' in Polytechnic of Sultan Abdul Halim Mu'adzam Shah on M-Learning. Asian Journal of Sociological Research, 1(1), 21-33.

Carbonell, K. B., Dailey-Hebert, A., \& Gijselaers, W. (2013). Unleashing the creative potential of faculty to create blended learning. The Internet and Higher Education, 18, 29-37.

Chang-Tik, C. (2018). Impact of learning styles on the community of inquiry presences in multi-disciplinary blended learning environments. Interactive Learning Environments, 26(6), 827-838.

Chong, S., Cheah, H. M., \& Low, E. L. (2010). Perceptions of student teachers in a blended learning environment. International Journal of Innovation and Learning, 8(4), 345-359.

Dakduk, S., Santalla-Banderali, Z., \& van der Woude, D. (2018). Acceptance of blended learning in executive education. SAGE Open, 8(3), 1-16.

Deng, R., Benckendorff, P., \& Gannaway, D. (2019). Progress and new directions for teaching and learning in MOOCs. Computers \& Education, 129, 48-60.

Edward, C. N., Asirvatham, D., \& Johar, M. G. M. (2018). Effect of blended learning and learners' characteristics on students' competence: An empirical evidence in learning oriental music. Education and Information Technologies, 23, 2587-2606.

Ekawati, A. D., Sugandi, L., \& Kusumastuti, D. L. (2017). Blended learning in higher education: Does gender influence the student satisfaction on blended learning?.ICIMTech ( $p p$ 160-164).

Elyakim, N., Reychav, I., Offir, B., \& McHaney, R. (2017). Perceptions of transactional distance in blended learning using location-based mobile devices. Journal of Educational Computing Research, 57(1), $131-169$.

Fesol, S. F. A., \& Salam, S. (2016). Towards MOOC for technical courses: A blended learning empirical analysis. $i$-USEr ( $p p$ 116-121).

Fisher, R., Perényi, Á., \& Birdthistle, N. (2018). The positive relationship between flipped and blended learning and student engagement, performance and satisfaction. Active Learning in Higher Education. https://doi.org/10.1177/1469787418801702

Garrison, D. R., \& Kanuka, H. (2004). Blended learning: Uncovering its transformative potential in higher education. The Internet and Higher Education, 7(2), 95-105.

Ghazal, S., Aldowah, H., \& Umar, I. (2017). Critical factors to learning management system acceptance and satisfaction in a blended learning environment. In Recent Trends in Information and Communication Technology, Springer, Cham (pp. 688-698).

Ghazal, S., Al-Samarraie, H., \& Aldowah, H. (2018). "I am still learning": Modeling LMS Critical success factors for promoting students' experience and satisfaction in a blended learning environment. IEEE Access.

Ghazali, R., Soon, C. C., Has, Z., Hassan, S. N. S., \& Hanafi, D. (2018). The effectiveness of blended learning approach with Student's perceptions in control systems engineering course. International Journal of Human and Technology Interaction (IJHaTI), 2(2), 103-108.

Ginns, P., \& Ellis, R. (2007). Quality in blended learning: Exploring the relationships between on-line and face-to-face teaching and learning. The Internet and Higher Education, 10(1), 53-64.

Graham, C. R. (2013). Emerging practice and research in blended learning. Handbook of Distance Education, 3, 333-350.

Graham, R. C., Burgoyne, N., Cantrell, P., Smith, L., St Clair, L., \& Harris, R. (2009). Measuring the TPACK confidence of inservice science teachers. TechTrends, 53(5), 70-79.

Graham, C. R., Woodfield, W., \& Harrison, J. B. (2013). A framework for institutional adoption and implementation of blended learning in higher education. The Internet and Higher Education, 18, 4-14.

Guillén-Gámez, F. D., Mayorga-Fernández, M. J., \& Álvarez-García, F. J. (2020). A study on the actual use of digital competence in the practicum of education degree. Technology, Knowledge and Learning, 25, $667-684$.

Güzer, B., \& Caner, H. (2014). The past, present and future of blended learning: an in depth analysis of literature. Procedia-Social and Behavioral Sciences, 116, 4596-4603. 
Haron, H., Abbas, W. F., \& Rahman, N. A. A. (2012). The adoption of blended learning among Malaysian academicians. Procedia-Social and Behavioral Sciences, 67, 175-181.

Heinze, A., \& Procter, C. T. (2004). Reflections on the use of blended learning.

Holton, E. F., III, Coco, M. L., Lowe, J. L., \& Dutsch, J. V. (2006). Blended delivery strategies for competency-based training. Advances in Developing Human Resources, 8(2), 210-228.

Ifenthaler, D., Sampson, D. G., \& Spector, J. M. (2015). Interactions between cognitive psychology, educational technology, and computing in the digital age. Technology, Knowledge and Learning, 20(2), 129-131.

Ifenthaler, D., \& Widanapathirana, C. (2014). Development and validation of a learning analytics framework: Two case studies using support vector machines. Technology, Knowledge and Learning, 19(12), 221-240.

Isa, W. A. R. W. M., Lokman, A. M., Mustapa, M. N., Sah, I. N. M., Hamdan, A. R., \& Luaran, J. E. (2015). Exploring the adoption of blended learning: Case of mobile learning. In AIMS, (pp. 359-364).

Ismail, M. E., Hamzah, N., Ariffin, A., Ismail, I. M., Daud, K. A. M., Utami, P., et al. (2018b). The acceptance of MOOC among TVET students in higher education: An observation. Journal Pendidikan, 15(2), 1-10.

Ismail, A. O., Mahmood, A. K., \& Abdelmaboud, A. (2018a). Factors influencing academic performance of students in blended and traditional domains. International Journal of Emerging Technologies in Learning, 13(02), 170-187.

Kaur, M. (2013). Blended learning-its challenges and future. Procedia-Social and Behavioral Sciences, $93,612-617$.

Kaur, A., \& Ahmed, A. (2006). E-learning challenges as perceived by communities of practice: Open University Malaysia's experiences. Asian Association of Open Universities Journal, 2(1), 51-65.

Kitchenham, B., \& Charters, S. (2007). Guidelines for performing systematic literature reviews in software engineering. Software Engineering Group, School of Computer Science and Mathematics, Keele University (pp 1-57)

Klentien, U., \& Wannasawade, W. (2016). Development of blended learning model with virtual science laboratory for secondary students. Procedia-Social and Behavioral Sciences, 217, 706-711.

Koehler, M., \& Mishra, P. (2009). What is technological pedagogical content knowledge (TPACK)? Contemporary Issues in Technology and Teacher Education, 9(1), 60-70.

Koohang, A. (2008). A learner-centred model for blended learning design. International Journal of innovation and learning, 6(1), 76-91.

Kumar, R., \& Pande, N. (2017). Technology-mediated learning paradigm and the blended learning ecosystem: What works for working professionals? Procedia Computer Science, 122, 1114-1123.

Van Laer, S., \& Elen, J. (2020). Adults' self-regulatory behaviour profiles in blended learning environments and their implications for design. Technology, Knowledge and Learning, 25, 509-539.

Lai, S. Q., Lee, C. L., Yeh, Y. J., \& Ho, C. T. (2005). A study of satisfaction in blended learning for small and medium enterprises. International Journal of Innovation and Learning, 2(3), 319-334.

Lin, W. S., \& Wang, C. H. (2012). Antecedences to continued intentions of adopting e-learning system in blended learning instruction: A contingency framework based on models of information system success and task-technology fit. Computers \& Education, 58(1), 88-99.

López-Pérez, M. V., Pérez-López, M. C., \& Rodríguez-Ariza, L. (2011). Blended learning in higher education: Students' perceptions and their relation to outcomes. Computers \& Education, 56(3), 818-826.

Machado, C. (2007). Developing an e-readiness model for higher education institutions: Results of a focus group study. British Journal of Educational Technology, 38(1), 72-82.

Maulan, S. B., \& Ibrahim, R. (2012). The teaching and learning of English for academic purposes in blended environment. Procedia-Social and Behavioral Sciences, 67, 561-570.

Mercado, C. (2008). Readiness assessment tool for an e-learning environment implementation. Special Issue of the International Journal of the Computer, the Internet and Management, 16, 18-21.

Mirabolghasemi, M., Iahad, N. A., \& Yadegaridehkordi, E. (2011). Investigating the dynamic relationships among the indicators of the community of inquiry model in blended learning. In International Conference on Research and Innovation in Information Systems (pp 1-5).

Mohd, I. H., Hussein, N., Aluwi, A. H., \& Omar, M. K. (2016). Enhancing students engagement through blended learning satisfaction and lecturer support. In ICEED ( $p p$ 175-180).

Moskal, P., Dziuban, C., \& Hartman, J. (2013). Blended learning: A dangerous idea? The Internet and Higher Education, 18, 15-23.

Mustapa, M. A. S., Ibrahim, M., \& Yusoff, A. (2015). Engaging vocational college students through blended learning: Improving class attendance and participation. Procedia-Social and Behavioral Sciences, 204, 127-135. 
Nguyen, V. A. (2017). Towards the implementation of an assessment-centred blended learning framework at the course level: A case study in a Vietnamese national university. The International Journal of Information and Learning Technology, 34(1), 20-30.

Owston, R., York, D., \& Malhotra, T. (2019). Blended learning in large enrolment courses: Student perceptions across four different instructional models. Australasian Journal of Educational Technology, 35(5), 29-45.

Ozkan, S., \& Koseler, R. (2009). Multi-dimensional students' evaluation of e-learning systems in the higher education context: An empirical investigation. Computers \& Education, 53(4), 1285-1296.

Padilla-MeléNdez, A., Del Aguila-Obra, A. R., \& Garrido-Moreno, A. (2013). Perceived playfulness, gender differences and technology acceptance model in a blended learning scenario. Computers \& Education, 63, 306-317.

Park, Y., Yu, J. H., \& Jo, I. H. (2016). Clustering blended learning courses by online behavior data: A case study in a Korean higher education institute. The Internet and Higher Education, 29, 1-11.

Poon, J. (2012). Use of blended learning to enhance the student learning experience and engagement in property education. Property Management, 30(2), 129-156.

Poon, J. (2014). A cross-country comparison on the use of blended learning in property education. Property Management, 32(2), 154-175.

Porter, W. W., \& Graham, C. R. (2016). Institutional drivers and barriers to faculty adoption of blended learning in higher education. British Journal of Educational Technology, 47(4), 748-762.

Porter, W. W., Graham, C. R., Bodily, R. G., \& Sandberg, D. S. (2016). A qualitative analysis of institutional drivers and barriers to blended learning adoption in higher education. The Internet and HIGHER EDUCATION, 28, 17-27.

Porter, W. W., Graham, C. R., Spring, K. A., \& Welch, K. R. (2014). Blended learning in higher education: Institutional adoption and implementation. Computers \& Education, 75, 185-195.

Prasad, P. W. C., Maag, A., Redestowicz, M., \& Hoe, L. S. (2018). Unfamiliar technology: Reaction of international students to blended learning. Computers \& Education, 122, 92-103.

Rahman, N. A. A., Hussein, N., \& Aluwi, A. H. (2015). Satisfaction on blended learning in a public higher education institution: What factors matter? Procedia-Social and Behavioral Sciences, 211, 768-775.

Ramakrisnan, P., Yahya, Y. B., Hasrol, M. N. H., \& Aziz, A. A. (2012). Blended learning: a suitable framework for e-learning in higher education. Procedia-Social and Behavioral Sciences, 67, 513-526.

Roszak, M., Kołodziejczak, B., Kowalewski, W., \& Ren-Kurc, A. (2014). Academic blended learning-competences and tools. International Journal of Continuing Engineering Education and Life Long Learning, 24(3-4), 286-301.

Sahin, I. (2011). Development of survey of technological pedagogical and content knowledge (TPACK). Turkish Online Journal of Educational Technology-TOJET, 10(1), 97-105.

San Pedro, M. O. Z., Baker, R. S., \& Heffernan, N. T. (2017). An integrated look at Middle School engagement and learning in digital environments as precursors to college attendance. Technology, Knowledge and Learning, 22(3), 243-270.

Sari, R., \& Karsen, M. (2016). An empirical study on blended learning to improve quality of learning in higher education. ICIMTech (pp 235-240).

Savara, V., \& Parahoo, S. (2018). Unraveling determinants of quality in blended learning: Are there genderbased differences? International Journal of Quality \& Reliability Management, 35(9), 2035-2051.

Schmidt, D. A., Baran, E., Thompson, A. D., Mishra, P., Koehler, M. J., \& Shin, T. S. (2009). Technological pedagogical content knowledge (TPACK) the development and validation of an assessment instrument for preservice teachers. Journal of research on Technology in Education, 42(2), 123-149.

So, H. J., \& Brush, T. A. (2008). Student perceptions of collaborative learning, social presence and satisfaction in a blended learning environment: Relationships and critical factors. Computers \& education, 51(1), 318-336.

Spring, K. J., Graham, C. R., \& Hadlock, C. A. (2016). The current landscape of international blended learning. International Journal of Technology Enhanced Learning, 8(1), 84-102.

Subramaniam, S. R., \& Muniandy, B. (2019). The effect of flipped classroom on students' engagement. Technology, Knowledge and Learning, 24(3), 355-372.

Sun, Z., \& Qiu, X. (2017). Developing a blended learning model in an EFL class. International Journal of Continuing Engineering Education and Life Long Learning, 27(1-2), 4-21.

Tahar, N. F., Mokhtar, R., Jaafar, N. H., Zamani, N. D., Sukiman, S. A., \& Ismail, Z. (2013). Students' satisfaction on blended learning: The use of factor analysis. IC $3 e$ ( $\mathrm{pp} 51-56)$.

Tulaboev, A. (2013). Blended learning approach with web 2.0 tools. ICRIIS (pp. 118-122).

Tuparova, D., \& Tuparov, G. (2011). Implementation of blended learning scenarios for training of school teachers. ICL, (pp 285-289).

Ustunel, H. H., \& Tokel, S. T. (2018). Distributed scaffolding: Synergy in technology-enhanced learning environments. Technology, Knowledge and Learning, 23(1), 129-160. 
Wai, C. C., \& Seng, E. L. K. (2015). Measuring the effectiveness of blended learning environment: A case study in Malaysia. Education and Information Technologies, 20(3), 429-443.

Wang, L., Ertmer, P. A., \& Newby, T. J. (2004). Increasing preservice teachers' self-efficacy beliefs for technology integration. Journal of Research on Technology in Education, 36(3), 231-250.

Wong, L., Tatnall, A., \& Burgess, S. (2014). A framework for investigating blended learning effectiveness. Education Training, 56(2/3), 233-251.

Yeou, M. (2016). An investigation of students' acceptance of moodle in a blended learning setting using technology acceptance model. Journal of Educational Technology Systems, 44(3), 300-318.

Zhu, Y., Au, W., \& Yates, G. (2016). University students' self-control and self-regulated learning in a blended course. The Internet and higher education, 30, 54-62.

Publisher's Note Springer Nature remains neutral with regard to jurisdictional claims in published maps and institutional affiliations.

\section{Affiliations}

Bokolo Anthony Jr. ${ }^{1}$ (D) Adzhar Kamaludin ${ }^{2} \cdot$ Awanis Romli ${ }^{2}$.

Anis Farihan Mat Raffei ${ }^{2} \cdot$ Danakorn Nincarean A. L. Eh Phon ${ }^{2} \cdot$ Aziman Abdullah $^{2}$. Gan Leong Ming ${ }^{2}$

Adzhar Kamaludin

adzhar@ump.edu.my

Awanis Romli

awanis@ump.edu.my

Anis Farihan Mat Raffei

anisfarihan@ump.edu.my

Danakorn Nincarean A. L. Eh Phon

danakorn@ump.edu.my

Aziman Abdullah

aziman@ump.edu.my

Gan Leong Ming

ming@ump.edu.my7

1 Department of Computer Science, Norwegian University of Science and Technology, NTNU, 7491 Trondheim, Norway

2 Universiti Malaysia Pahang, 26300 Gambang, Pahang, Malaysia 